\title{
Air-water $\mathrm{CO}_{2}$ evasion from US East Coast estuaries
}

\author{
Goulven Gildas Laruelle ${ }^{1}$, Nicolas Goossens ${ }^{1}$, Sandra Arndt ${ }^{1,2}$, Wei-Jun Cai ${ }^{3}$, and Pierre Regnier ${ }^{1}$ \\ ${ }^{1}$ Department Geosciences, Environment and Society, Université Libre de Bruxelles, Brussels, Belgium \\ ${ }^{2}$ School of Geographical Sciences, University of Bristol, Bristol, UK \\ ${ }^{3}$ School of Marine Science and Policy, University of Delaware, Newark, Delaware, USA
}

Correspondence to: Goulven Gildas Laruelle (goulven.gildas.laruelle@ulb.ac.be)

Received: 4 July 2016 - Discussion started: 18 July 2016

Revised: 27 March 2017 - Accepted: 13 April 2017 - Published: 15 May 2017

\begin{abstract}
This study presents the first regional-scale assessment of estuarine $\mathrm{CO}_{2}$ evasion along the US East Coast (25$45^{\circ} \mathrm{N}$ ). The focus is on 42 tidal estuaries, which together drain a catchment of $697000 \mathrm{~km}^{2}$ or $76 \%$ of the total area within this latitudinal band. The approach is based on the Carbon-Generic Estuary Model (C-GEM) that allows the simulation of hydrodynamics, transport, and biogeochemistry for a wide range of estuarine systems using readily available geometric parameters and global databases of seasonal climatic, hydraulic, and riverine biogeochemical information. Our simulations, performed using conditions representative of the year 2000, suggest that, together, US East Coast estuaries emit $1.9 \mathrm{Tg} \mathrm{C} \mathrm{yr}^{-1}$ in the form of $\mathrm{CO}_{2}$, which corresponds to about $40 \%$ of the carbon inputs from rivers, marshes, and mangroves. Carbon removal within estuaries results from a combination of physical (outgassing of supersaturated riverine waters) and biogeochemical processes (net heterotrophy and nitrification). The $\mathrm{CO}_{2}$ evasion and its underlying drivers show important variations across individual systems, but reveal a clear latitudinal pattern characterized by a decrease in the relative importance of physical over biogeochemical processes along a north-south gradient. Finally, the results reveal that the ratio of estuarine surface area to the river discharge, $S / Q$ (which has a scale of per meter discharged water per year), could be used as a predictor of the estuarine carbon processing in future regional- and globalscale assessments.
\end{abstract}

\section{Introduction}

Carbon fluxes along the land-ocean aquatic continuum are currently receiving increasing attention because of their recently recognized role in the global carbon cycle and anthropogenic $\mathrm{CO}_{2}$ budget (Bauer et al., 2013; Regnier et al., 2013a; LeQuéré et al., 2014, 2015). Estuaries are important reactive conduits along this continuum, which links the terrestrial and marine global carbon cycles (Cai, 2011). Large amounts of terrestrial carbon transit through these systems, where they mix with carbon from autochthonous, as well as marine, sources. During estuarine transit, heterotrophic processes degrade a fraction of the allochthonous and autochthonous organic carbon inputs, supporting a potentially significant, yet poorly quantified $\mathrm{CO}_{2}$ evasion flux to the atmosphere. Recent estimates suggest that $0.15-0.25 \mathrm{PgC} \mathrm{yr}^{-1}$ is emitted from estuarine systems worldwide (Borges and Abril, 2012; Cai, 2011; Laruelle et al., 2010; Regnier et al., 2013a; Laruelle et al., 2013, Bauer et al., 2013). Thus, in absolute terms, the global estuarine $\mathrm{CO}_{2}$ evasion corresponds to about $15 \%$ of the open-ocean $\mathrm{CO}_{2}$ uptake despite the much smaller total surface area.

Currently, estimates of regional and global estuarine $\mathrm{CO}_{2}$ emissions are mainly derived on the basis of data-driven approaches that rely on the extrapolation of a small number of local measurements (Cai, 2011; Chen et al., 2013; Laruelle et al., 2013). These approaches fail to capture the spatial and temporal heterogeneity of the estuarine environment (Bauer et al., 2013) and are biased towards anthropogenically influenced estuarine systems located in industrialized countries (Regnier et al., 2013a). Even in the best surveyed regions of the world (e.g., Australia, western Europe, North America, or China) observations are merely available for a small number 
of estuarine systems. In addition, if available, data sets are generally of low spatial and temporal resolution. As a consequence, data-driven approaches can only provide first-order estimates of regional and global estuarine $\mathrm{CO}_{2}$ emissions.

Integrated model-data approaches can help here, as models provide the means to extrapolate over temporal and spatial scales and allow the disentanglement of the complex and very dynamic network of physical and biogeochemical processes that control estuarine $\mathrm{CO}_{2}$ emissions. Over the past decades, increasingly complex process-based models have been applied, in combination with local data, to elucidate the coupled carbon-nutrient cycles on the scale of individual estuaries (e.g., O'Kane, 1980; Soetaert and Herman, 1995; Vanderborght et al., 2002; Lin et al., 2007; Arndt et al., 2009; Cerco et al., 2010; Baklouti et al., 2011). However, the application of such model approaches remains limited to the local scale due to their high data requirements for calibration and validation (e.g., bathymetric and geometric information and boundary conditions), as well as the high computational demand associated with resolving the complex interplay of physical and biogeochemical processes on the relevant temporal and spatial scales (Regnier et al., 2013b). Complex process-based models are thus not suitable for application on a regional or global scale and, as a consequence, the estuarine carbon filter is, despite its increasingly recognized role in regional and global carbon cycling (e.g., Bauer et al., 2013), typically not taken into account in model-derived regional or global carbon budgets (Bauer et al., 2013). The lack of regional and global model approaches that could be used as stand-alone applications or that could be coupled to regional terrestrial river network models (e.g., Global NEWS, Seitzinger et al., 2005; Mayorga et al., 2010; SPARROW, Schwarz et al., 2006) and continental shelf models (e.g., Hofmann et al., 2011) is thus critical.

The Carbon-Generic Estuary Model (C-GEM (v1.0); Volta et al., 2014) has been developed with the aim of providing such a regional and/or global modeling tool that can help improve existing, observationally derived first-order estimates of estuarine $\mathrm{CO}_{2}$ emissions. C-GEM (v1.0) has been specifically designed to reduce data requirements and computational demand and, thus, tackles the main impediments to the application of estuarine models on a regional or global scale. The approach takes advantage of the mutual dependency between estuarine geometry and hydrodynamics in alluvial estuaries and uses an idealized representation of the estuarine geometry to support the hydrodynamic calculations. It thus allows running steady-state or fully transient annual to multi-decadal simulations for a large number of estuarine systems, using geometric information readily available through maps or remote sensing images. Although the development of such a regional-global tool inevitably requires simplification, careful model evaluations have shown that, despite the geometric simplification, C-GEM provides an accurate description of the hydrodynamics, transport, and biogeochemistry in tidal estuaries (Volta et al., 2014). In ad- dition, the model approach was successfully used to quantify the contribution of different biogeochemical processes to $\mathrm{CO}_{2}$ air-water fluxes in an idealized, funnel-shaped estuary forced by typical summer conditions characterizing a temperate western European climate (Regnier et al., 2013b). Volta et al. (2016b) further investigated the effect of estuarine geometry on the $\mathrm{CO}_{2}$ outgassing using three idealized systems and subsequently established the first regional carbon budget for estuaries surrounding the North Sea by explicitly simulating the six largest systems of the area (Volta et al., 2016a), including the Scheldt and the Elbe, for which detailed validation was performed.

Here, we extend the domain of application of C-GEM (v1.0) to quantify $\mathrm{CO}_{2}$ exchange fluxes, as well as the overall organic and inorganic carbon budgets for the full suite of estuarine systems located along the entire US East Coast, one of the most intensively monitored regions in the world. A unique set of regional data, including partial pressure of $\mathrm{CO}_{2}$ in riverine and continental shelf waters $\left(p \mathrm{CO}_{2}\right.$; Signorini et al., 2013; Laruelle et al., 2015), riverine biogeochemical characteristics (Lauerwald et al., 2013), estuarine eutrophication status (Bricker et al., 2007), and estuarine morphology (NOAA, 1985) is available. These comprehensive data sets are complemented by local observations of carbon cycling and $\mathrm{CO}_{2}$ fluxes in selected, individual estuarine systems (see Laruelle et al., 2013, for a review), making the US East Coast an ideal region for a first, fully explicit regional evaluation of $\mathrm{CO}_{2}$ evasion resolving every major tidal estuary along the selected coastal segment. The scale addressed in the present study is unprecedented so far $(>3000 \mathrm{~km}$ of coastline) and covers a wide range of estuarine morphological features, climatic conditions, land-use and land cover types, and urbanization levels. The presented study will not only allow a further evaluation of C-GEM (v1.0) but will also provide the first regional-scale assessment of estuarine $\mathrm{CO}_{2}$ evasion along the US East Coast $\left(25-45^{\circ} \mathrm{N}\right)$. Furthermore, it will help explore general relationships between carbon cycling and $\mathrm{CO}_{2}$ evasion, and readily available estuarine geometrical parameters.

After a description of the model itself and of the data set used to set up the simulations, a local validation is presented, which includes salinity, $p \mathrm{CO}_{2}$, and $\mathrm{pH}$ longitudinal profiles for two well-monitored systems (the Delaware Bay and the Altamaha River estuary). The averaged rates of $\mathrm{CO}_{2}$ exchange at the air-water interface for each year simulated by the model for 13 individual estuaries are also compared with observed values reported in the literature. Next, regional-scale simulations for 42 tidal estuaries of the US East Coast provide seasonal and yearly integrated estimates of the net ecosystem metabolism (NEM), $\mathrm{CO}_{2}$ evasion, and carbon-filtering capacity (CFilt). Model results are then used to elucidate the estuarine biogeochemical behavior along the latitudinal transect encompassed by the present study (30$45^{\circ} \mathrm{N}$ ). Finally, our results are used to derive general rela- 


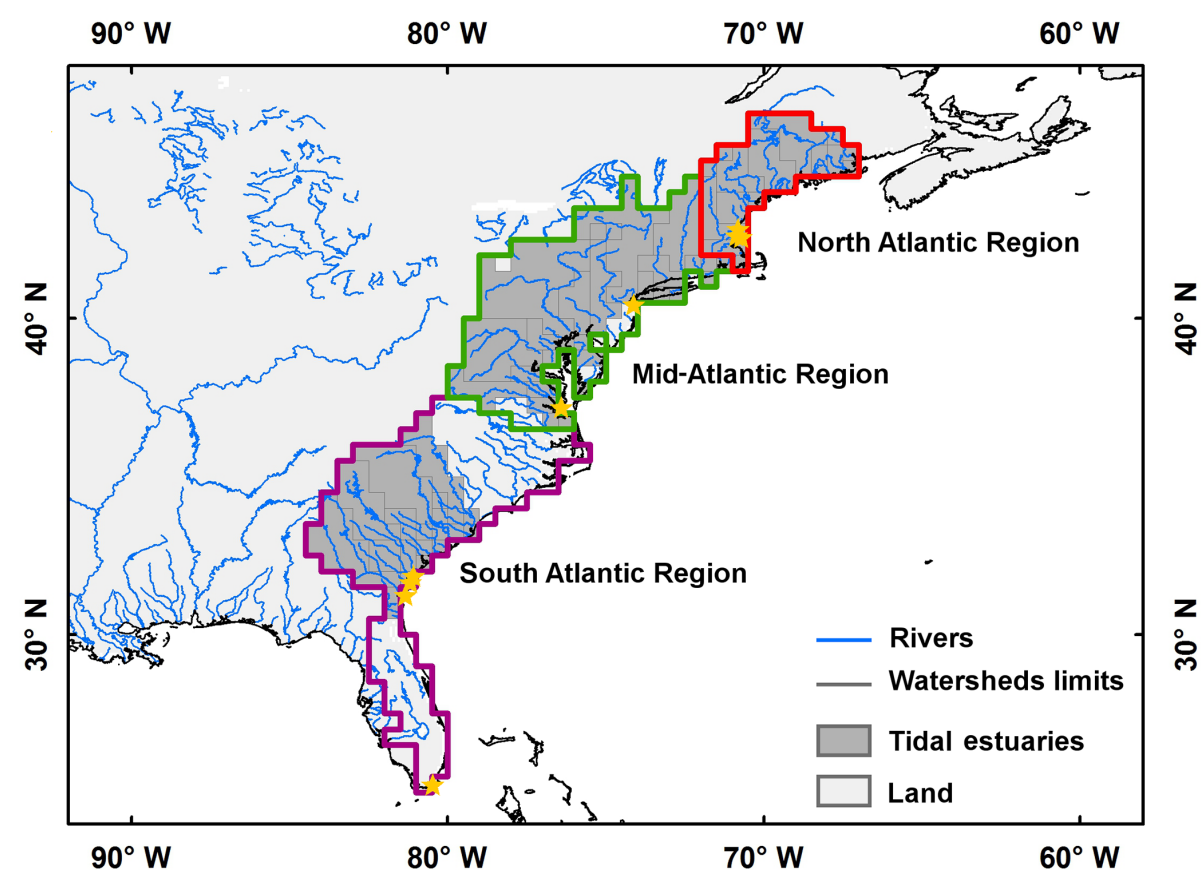

Figure 1. Limits of the $0.5^{\circ}$ resolution watersheds corresponding to tidal estuaries of the US East Coast. Three subregions are delimited with colors, and orange stars represent the location of previous studies.

tionships between carbon cycling and $\mathrm{CO}_{2}$ evasion, and readily available estuarine geometrical parameters.

\section{Regional description and model approach}

\subsection{Observation-based carbon budget for the US East Coast}

The study area covers the Atlantic coast of the United States (Fig. 1), from the southern tip of Florida $\left(25^{\circ} \mathrm{N}\right)$ to Cobscook Bay $\left(45^{\circ} \mathrm{N}\right)$ at the United Sates-Canada boundary. This area encompasses distinct climatic zones and land cover types and exhibits a variety of morphologic features (Fig. 1). The region can be subdivided into several subregions following a latitudinal gradient (Signorini et al., 2013). In this study, we define three subregions following the boundaries suggested by the COSCAT segmentation (Meybeck et al., 2006; Laruelle et al., 2013) and the further subdivision described in Laruelle et al. (2015). From north to south, the regions are called the North Atlantic (NAR), Mid-Atlantic (MAR), and South Atlantic (SAR) regions (Fig. 1). Total carbon inputs from watersheds to US East Coast estuaries (Table 1) have been estimated to range from 4.0 to $10.7 \mathrm{Tg} \mathrm{C} \mathrm{yr}^{-1}$ (Mayorga et al., 2010; Shih et al., 2010; Stets and Strieg, 2012; Tian et al., 2010, 2012), consisting of dissolved organic carbon (DOC; 50\%), dissolved inorganic carbon (DIC; 40\%), and particulate organic carbon (POC; $\sim 10 \%$ ). In addition, a statistical approach has been applied to estuaries of the region to quantify organic carbon budgets and net ecosystem
Table 1. Estimates of total annual riverine input from watersheds to estuaries $\left(\mathrm{Tg} \mathrm{C} \mathrm{yr}^{-1}\right)$. The ranges are based on Stets and Striegl (2012), Global NEWS (Mayorga et al., 2010), Hartmann et al. (2009), SPARROW (Shih et al., 2010), and DLEM (Tian et al., 2010, 2012). Modified from Najjar et al. (2012).

\begin{tabular}{lrrrr}
\hline & DIC & DOC & POC & Total \\
\hline NAR & $0.2-0.8$ & $0.3-2.1$ & $0.1-0.2$ & $0.6-3.1$ \\
MAR & $1.4-1.8$ & $0.5-2.3$ & $0.1-0.3$ & $2.0-4.4$ \\
SAR & $0.4-1.4$ & $0.9-1.6$ & $0.1-0.2$ & $1.4-3.2$ \\
Total & $2.0-4.0$ & $1.7-6.0$ & $0.3-0.7$ & $4.0-10.7$ \\
\hline
\end{tabular}

productivity (NEP) using empirical models (Herrmann et al., 2015).

Recent studies estimated that, along the US East Coast, rivers emit $11.4 \mathrm{Tg} \mathrm{C} \mathrm{yr}^{-1}$ of $\mathrm{CO}_{2}$ to the atmosphere (Raymond et al., 2013), while continental shelf waters absorb between 3.4 and $5.4 \mathrm{Tg} \mathrm{Cyr}^{-1}$ of $\mathrm{CO}_{2}$ from the atmosphere (Signorini et al., 2013). A total of 13 local, annual mean estuarine $\mathrm{CO}_{2}$ flux estimates across the air-water interface based on measurements are also reported in the literature and are grouped along a latitudinal gradient (Table 2). Four of these estimates are located in the SAR: Sapelo Sound, Doboy Sound, Altamaha Sound (Jiang et al., 2008), and the Satilla River estuary (Cai and Wang, 1998). Three studies investigate $\mathrm{CO}_{2}$ fluxes in the MAR: the York River estuary (Raymond et al., 2000) and the Hudson River (Raymond et al., 1997). There is also a comprehensive $\mathrm{CO}_{2}$ flux study for 
the Delaware Estuary that will be published after the completion of this work (Joeseof et al., 2015). Six systems are located in the NAR: the Great Bay, the Little Bay, the Oyster estuary, the Bellamy estuary, the Cocheco estuary (Hunt et al., 2010, 2011), and the Parker River estuary (Raymond and Hopkinson, 2003). The mean annual flux per unit area from these local studies is $11.7 \pm 13.1 \mathrm{~mol} \mathrm{C} \mathrm{m}^{-2} \mathrm{yr}^{-1}$ and its extrapolation to the total estuarine surface leads to a regional $\mathrm{CO}_{2}$ evasion estimate of $3.8 \mathrm{Tg} \mathrm{C} \mathrm{yr}^{-1}$. This estimate is in line with that of Laruelle et al. (2013), which proposes an average $\mathrm{CO}_{2}$ emission rate of $10.8 \mathrm{~mol} \mathrm{C} \mathrm{m}^{-2} \mathrm{yr}^{-1}$, for the same region. Thus, $\mathrm{CO}_{2}$ outgassing could remove 35 to $95 \%$ of the riverine carbon loads during estuarine transit. About $75 \%$ of the air-water exchange occurs in tidal estuaries $\left(2.8 \mathrm{Tg} \mathrm{Cyr}^{-1}\right.$ ), while lagoons and small deltas contribute the remaining $25 \%$. Although these simple extrapolations from limited observational data are associated with large uncertainties, they highlight the potentially significant contribution of estuaries to the $\mathrm{CO}_{2}$ outgassing in the region. However, process-based quantifications of regional organic and inorganic $\mathrm{C}$ budgets, including air-water $\mathrm{CO}_{2}$ fluxes for the estuarine systems along the US East Coast, are not available.

\subsection{Selection of estuaries}

The National Estuarine Eutrophication Assessment (NEEA) survey (Bricker et al., 2007), which uses geospatial data from the NOAA Coastal Assessment Framework (CAF) (NOAA, 1985), was used to identify and characterize 58 estuarine systems discharging along the Atlantic coast of the United States. From this set, 42 tidal estuaries, defined as a river stretch of water that is tidally influenced (Dürr et al., 2011), were retained (Fig. 1) to be simulated by the C-GEM model, which is designed to represent such systems. Using outputs from terrestrial models (Hartmann et al., 2009; Mayorga et al., 2010), the cumulated riverine carbon loads for all the nontidal estuaries that are excluded from the present study amount to $0.9 \mathrm{Tg} \mathrm{Cyr}^{-1}$, which represents less than $15 \%$ of the total riverine carbon loads of the region. These 16 systems are located in the SAR (Eq. 10) and in the MAR (Eq. 6).

The northeastern part of the domain (NAR; Fig. 1; Table 1) includes 11 estuaries along the Gulf of Maine and the Scotian Shelf, covering a cumulative surface area of $558 \mathrm{~km}^{2}$. It includes drowned valleys, rocky shores, and a few tidal marshes. The climate is relatively cold (annual mean $=8{ }^{\circ} \mathrm{C}$ ) and the human influence is relatively limited because of low population density and low freshwater input. The mean estuarine water depth is $12.9 \mathrm{~m}$ and the mean tidal range is $2.8 \mathrm{~m}$.

The central zone (MAR) includes 18 tidal estuaries accounting for a total surface area of $9298 \mathrm{~km}^{2}$. The Chesapeake Bay and the Delaware estuaries alone contribute more than $60 \%$ to the surface area of the region. In this region, estuaries are drowned valleys with comparatively high river discharge and intense exchange with the ocean. Several

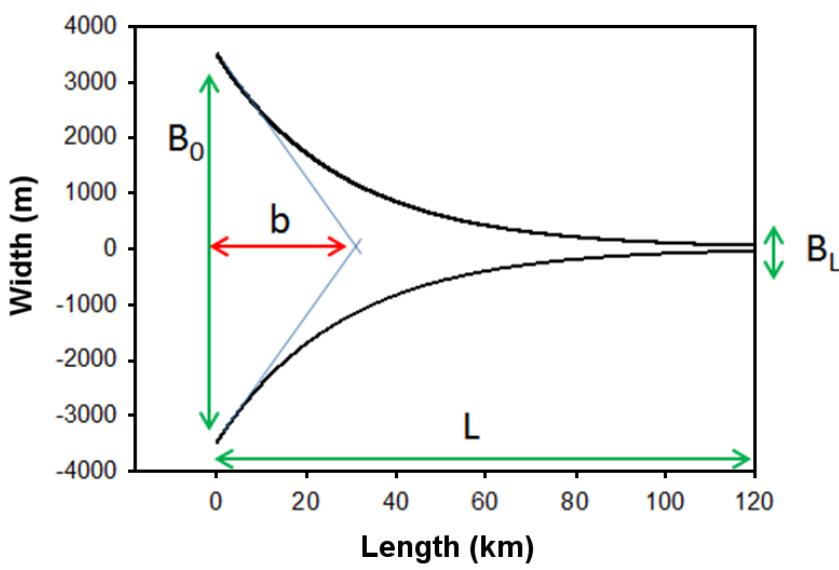

Figure 2. Idealized estuarine geometry and main parameters. Parameters indicated by green arrows are measured; $b$ is calculated. See Sect. 2.3.1 for further details.

coastal lagoons, characterized by a limited exchange with the ocean, are located here, but are not included in our analysis. The MAR is characterized by a mean annual temperature of $13{ }^{\circ} \mathrm{C}$ and is strongly impacted by human activities due to the presence of several large cities (e.g., New York, Washington, Philadelphia, Baltimore) and intense agriculture. The mean water depth is about $4.7 \mathrm{~m}$ and the tidal range is $0.8 \mathrm{~m}$.

The SAR includes 13 tidal estuaries covering a total surface area of $959 \mathrm{~km}^{2}$. These systems are generally dendritic and surrounded by extensive salt marshes. The climate is subtropical with an average annual temperature of $19^{\circ} \mathrm{C}$. Land use includes agriculture and industry, but the population density is generally low. Estuarine systems in the SAR are characterized by a shallow mean water depth of $2.9 \mathrm{~m}$ and a tidal range of $1.2 \mathrm{~m}$.

\subsection{Model setup}

The generic 1-D reactive-transport model (RTM) C-GEM (Volta et al., 2014) is used to quantify the estuarine carbon cycling in the 42 systems considered in this study. The approach is based on idealized geometries (Savenije, 2005; Volta et al., 2014) and is designed for regional- and globalscale applications (Regnier et al., 2013b; Volta et al., 2014, 2016a). The model approach builds on the premise that hydrodynamics exert a first-order control on estuarine biogeochemistry (Arndt et al., 2007; Friedrichs and Hofmann, 2001) and $\mathrm{CO}_{2}$ fluxes (Regnier et al., 2013a). The method takes advantage of the mutual dependence between geometry and hydrodynamics in tidal estuaries (Savenije, 1992) and the fact that, as a consequence, transport and mixing can be easily quantified from readily available geometric data (Regnier et al., 2013a; Savenije, 2005; Volta et al., 2016b). 
Table 2. Published local annually averaged estimates of $\overline{\mathrm{FCO}}_{2}$ in $\mathrm{mol} \mathrm{C} \mathrm{m}^{-2} \mathrm{yr}^{-1}$ for estuaries along the US East Coast.

\begin{tabular}{lrrrrl}
\hline \multirow{2}{*}{ Name } & Long $\left(^{\circ}\right)$ & Lat $\left(^{\circ}\right)$ & \multicolumn{2}{c}{$\overline{\mathrm{FCO}}_{2}$} & \multirow{2}{*}{ Reference } \\
\cline { 3 - 4 } & & & Observed & Modeled & \\
\hline Altamaha Sound & -81.3 & 31.3 & 32.4 & 72.7 & Jiang et al. (2008) \\
Bellamy & -70.9 & 43.2 & 3.6 & 3.9 & Hunt et al. (2010) \\
Cocheco & -70.9 & 43.2 & 3.1 & 3.9 & Hunt et al. (2010) \\
Doboy Sound & -81.3 & 31.4 & 13.9 & 25.7 & Jiang et al. (2008) \\
Great Bay & -70.9 & 43.1 & 3.6 & 3.9 & Hunt et al. (2011) \\
Little Bay & -70.9 & 43.1 & 2.4 & 3.9 & Hunt et al. (2011) \\
Oyster Bay & -70.9 & 43.1 & 4 & 3.9 & Hunt et al. (2011) \\
Parker River estuary & -70.8 & 42.8 & 1.1 & 3.9 & Raymond and Hopkinson (2003) \\
Sapelo Sound & -81.3 & 31.6 & 13.5 & 20.6 & Jiang et al. (2008) \\
Satilla River & -81.5 & 31 & 42.5 & 25.7 & Cai and Wang (1998) \\
York River & -76.4 & 37.2 & 6.2 & 8.1 & Raymond et al. (2000) \\
Hudson River & -74 & 40.6 & 13.5 & 15.5 & Raymond et al. (1997) \\
\hline
\end{tabular}
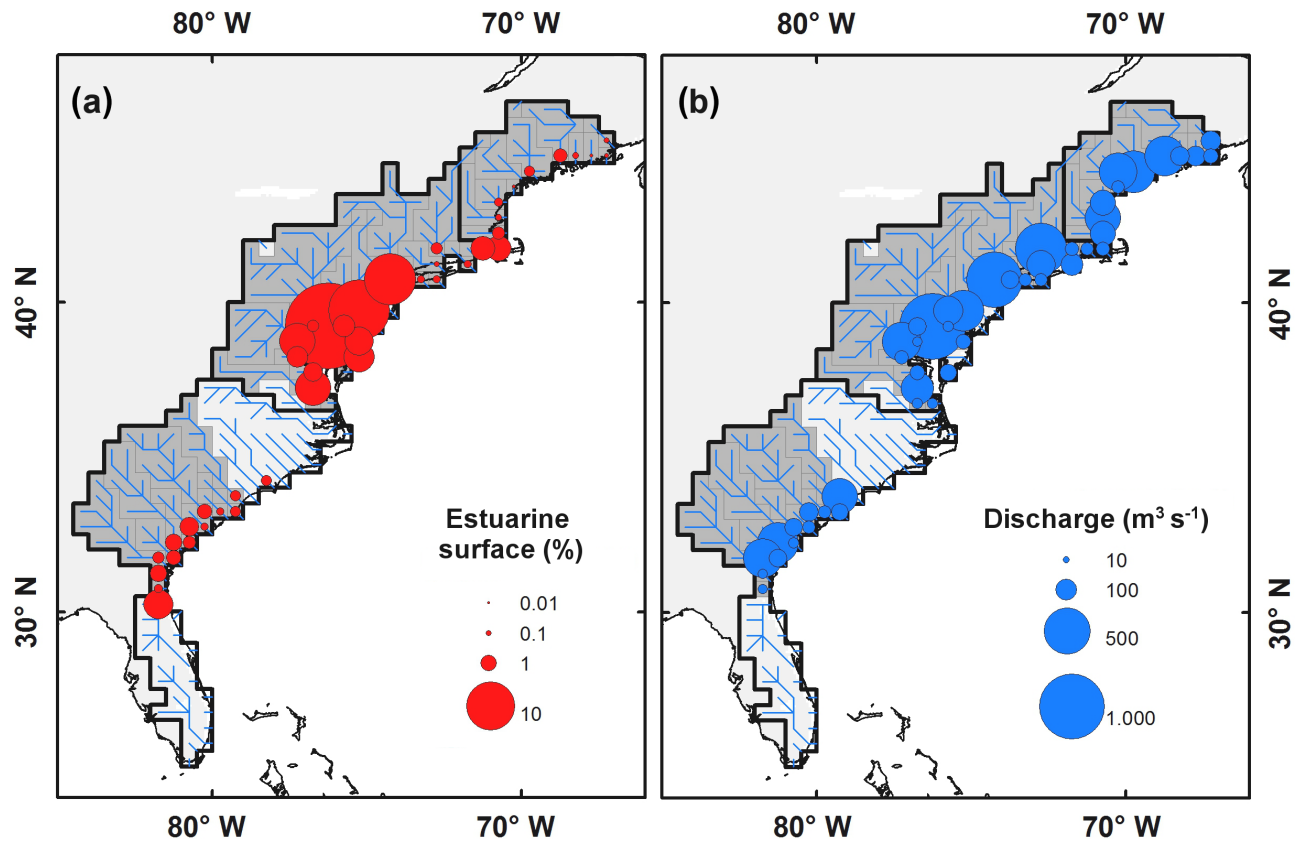

Figure 3. Estuarine surface area (a) and mean annual freshwater discharge (b) for each tidal estuary of the US East Coast. Estuarine surface area is expressed as a percentage of the entire surface area of the region $\left(19830 \mathrm{~km}^{2}\right)$.

\subsubsection{Description of idealized geometries for tidally averaged conditions}

Although tidal estuaries display a wide variety of shapes, they nevertheless share common geometric characteristics that are compatible with an idealized representation (Fig. 2; Savenije, 1986, 2005). For tidally averaged conditions, their width $B$ (or cross-sectional area A) can be described by an exponential decrease as a function of distance, $x$, from the mouth (Savenije, 1986, 2005).

$B=B 0 \times \exp \left(-\frac{x}{b}\right)$
$B(\mathrm{~m})$ is the tidally averaged width, $B 0(\mathrm{~m})$ the width at the mouth, $x(\mathrm{~m})$ the distance from the mouth $(x=0)$, and $b$ (m) the width convergence length (Fig. 2). The width convergence length, $b$, is defined as the distance between the mouth and the point at which the width is reduced to $B 0 e^{-1}$. It is directly related to the dominant hydrodynamic forcing. A high river discharge typically results in a prismatic channel with long convergence length (river-dominated estuary), while a large tidal range results in a funnel-shaped estuary with short convergence length (marine-dominated estuary). At the upstream boundary, the estuarine width is given by 
the following equation.

$B_{\mathrm{L}}=B 0 \times \exp \left(-\frac{L}{b}\right)$

$L$ denotes the total estuarine length (m) along the estuarine longitudinal axis.

The total estuarine surface $S\left(\mathrm{~m}^{2}\right)$ can be estimated by integrating Eq. (1) over the estuarine length.

$S=\int_{0}^{\mathrm{L}} B \mathrm{~d} x=b \times B 0 \times\left(1-\exp \left(-\frac{L}{b}\right)\right)$

The width convergence length is then calculated from $B 0$, $B_{\mathrm{L}}, L$, and the real estuarine surface area (SR) by inserting Eq. (2) in Eq. (3).

$b=\frac{S R}{B 0-B_{L}}$

$\mathrm{SR}$ is calculated for each system using the SRTM water body data (Fig. 3a), a geographical data set encoding highresolution worldwide coastal outlines in a vector format (NASA/NGA, 2003). While such a database exists for a wellmonitored region such as the US East Coast, resorting to using the idealized estuarine surface area $(S)$ is necessary in many other regions. The longitudinal mean, tidally averaged depth $h(\mathrm{~m})$ is obtained from the NEEA database (Bricker et al., 2007).

Using this idealized representation, the estuarine geometry can be defined by a limited number of parameters: the width at the mouth $\left(B_{0}\right)$, the estuarine length $(L)$, the estuarine width at the upstream limit $\left(B_{\mathrm{L}}\right)$, and the mean depth $h$. These parameters can be easily determined from local maps or Google Earth using geographic information systems (GISs) or they can be obtained from databases (NASA/NGA, 2003).

\subsubsection{Hydrodynamics, transport, and biogeochemistry}

Estuarine hydrodynamics are described by the onedimensional barotropic, cross-sectionally integrated mass and momentum conservation equations for a channel with arbitrary geometry (Nihoul and Ronday, 1976; Regnier et al., 1998; Regnier and Steefel, 1999).

$r_{\mathrm{s}} \frac{\partial A}{\partial t}+\frac{\partial Q}{\partial x}=0$

$\frac{\partial U}{\partial t}+U \frac{\partial U}{\partial x}=-g \frac{\partial \zeta}{\partial x}-g \frac{U|U|}{C_{z}^{2} H}$

$t$ is the time (s), $x$ the distance along the longitudinal axis (m), $A$ the cross-sectional area $A=H \times B\left(\mathrm{~m}^{2}\right), Q$ the crosssectional discharge $Q=A \times U\left(\mathrm{~m}^{3} \mathrm{~s}^{-1}\right), U$ the flow velocity $Q / A\left(\mathrm{~m} \mathrm{~s}^{-1}\right), r_{\mathrm{s}}$ the storage ratio $r_{\mathrm{s}}=B_{\mathrm{s}} / B, B_{\mathrm{s}}$ the storage width $(\mathrm{m}), g$ the gravitational acceleration $\left(\mathrm{m} \mathrm{s}^{-2}\right), \xi$ the elevation (m), $H$ the total water depth $H=h+\xi(x, t)(\mathrm{m})$, and
$C_{z}$ the Chézy coefficient $\left(\mathrm{m}^{1 / 2} \mathrm{~s}^{-1}\right)$. The coupled partial differential equations (Eqs. 5 and 6) are solved by specifying the elevation $\xi_{0}(t)$ at the estuarine mouth and the river discharge $Q_{\mathrm{r}}(t)$ at the upstream limit of the model domain.

The one-dimensional, tidally resolved, advectiondispersion equation for a constituent of concentration $C(x, t)$ in an estuary can be written as follows (e.g., Pritchard, 1958).

$\frac{\partial C}{\partial t}+\frac{Q}{A} \frac{\partial C}{\partial x}=\frac{1}{A} \frac{\partial}{\partial x}\left(A D \frac{\partial C}{\partial x}\right)+P$

$Q(x, t)$ and $A(x, t)$ denote the cross-sectional discharge and area, respectively, and are provided by the hydrodynamic model (Eqs. 5 and 6$). P(x, t)$ is the sum of all production and consumption process rates affecting the concentration of the constituent. The effective dispersion coefficient $D$ $\left(\mathrm{m}^{2} \mathrm{~s}^{-1}\right)$ implicitly accounts for dispersion mechanisms associated with sub-grid scale processes (Fischer, 1976; Regnier et al., 1998). In general, $D$ is maximal near the sea, decreases upstream, and becomes virtually zero near the tail of the salt intrusion curve (Preddy, 1954; Kent, 1958; Ippen and Harleman, 1961; Stigter and Siemons, 1967). The effective dispersion at the estuarine mouth can be quantified by the following relation (Savenije, 1986).

$D_{0}=26 \times\left(h_{0}\right)^{1.5} \times(N \times g)^{0.5}$

$h_{0}(\mathrm{~m})$ is the tidally averaged water depth at the estuarine mouth and $N$ is the dimensionless Canter-Cremers estuary number defined as the ratio of the freshwater entering the estuary during a tidal cycle to the volume of salt water entering the estuary over a tidal cycle (Simmons, 1955).

$N=\frac{Q_{\mathrm{b}} \times T}{P}$

In this equation, $Q_{\mathrm{b}}$ is the bank-full discharge $\left(\mathrm{m}^{3} \mathrm{~s}^{-1}\right), T$ is the tidal period (s), and $P$ is the tidal prism $\left(\mathrm{m}^{3}\right)$. For each estuary, $N$ can thus be calculated directly from the hydrodynamic model. The variation in $D$ along the estuarine gradient can be described by Van der Burgh's equation (Savenije, 1986).

$\frac{\partial D}{\partial x}=-K \frac{Q_{\mathrm{r}}}{A}$

$K$ is the dimensionless Van der Burgh's coefficient and the minus sign indicates that $D$ increases in the downstream direction (Savenije, 2012). The Van der Burgh's coefficient is a shape factor that has values between 0 and 1 (Savenije, 2012), and it is a function of estuarine geometry for tidally average conditions. Therefore, each estuarine system has its own characteristic $K$ value, which correlates with geometric and hydraulic scales (Savenije, 2005). Based on a regression analysis covering a set of 15 estuaries, it has been proposed to constrain $K$ from the estuarine geometry (Savenije, 1992).

$K=4.32 \times \frac{h_{0}^{0.36}}{B_{0}^{0.21} \times b^{0.14}}$ with $0<K<1$ 
Table 3. State variables and processes explicitly implemented in CGEM.

\begin{tabular}{|c|c|c|}
\hline \multicolumn{3}{|l|}{ State variables } \\
\hline Name & Symbol & Unit \\
\hline Suspended particulate matter & SPM & $\mathrm{gL}^{-1}$ \\
\hline Total organic carbon & TOC & $\mu \mathrm{M} \mathrm{C}$ \\
\hline Nitrate & $\mathrm{NO}_{3}$ & $\mu \mathrm{M} \mathrm{N}$ \\
\hline Ammonium & $\mathrm{NH}_{4}$ & $\mu \mathrm{M} \mathrm{N}$ \\
\hline Phosphate & DIP & $\mu \mathrm{M} \mathrm{P}$ \\
\hline Dissolved oxygen & DO & $\mu \mathrm{M} \mathrm{O}_{2}$ \\
\hline Phytoplankton & Phy & $\mu \mathrm{M} \mathrm{C}$ \\
\hline Dissolved silica & $\mathrm{DSi}$ & $\mu \mathrm{M} \mathrm{Si}$ \\
\hline Dissolved inorganic carbon & DIC & $\mu \mathrm{M} \mathrm{C}$ \\
\hline \multicolumn{3}{|l|}{ Biogeochemical reactions } \\
\hline Gross primary production & GPP & $\mu \mathrm{M} \mathrm{Cs} s^{-1}$ \\
\hline Net primary production & NPP & $\mu \mathrm{M} \mathrm{Cs} s^{-1}$ \\
\hline Phytoplankton mortality & M & $\mu \mathrm{M} \mathrm{C} \mathrm{s}{ }^{-1}$ \\
\hline Aerobic degradation & $\mathrm{R}$ & $\mu \mathrm{M} \mathrm{Cs}^{-1}$ \\
\hline Denitrification & $\mathrm{D}$ & $\mu \mathrm{MC} s^{-1}$ \\
\hline Nitrification & $\mathrm{N}$ & $\mu \mathrm{M} \mathrm{N} \mathrm{s}^{-1}$ \\
\hline $\mathrm{O}_{2}$ exchange with the atmosphere & $\mathrm{FO}_{2}$ & $\mu \mathrm{M} \mathrm{O}_{2} \mathrm{~s}^{-1}$ \\
\hline $\mathrm{CO}_{2}$ exchange with the atmosphere & $\mathrm{FCO}_{2}$ & $\mu \mathrm{M} \mathrm{Cs}^{-1}$ \\
\hline SPM erosion & $\mathrm{E}_{S P M}$ & $\mathrm{gL}^{-1} \mathrm{~s}^{-1}$ \\
\hline SPM deposition & $\mathrm{D}_{S P M}$ & $\mathrm{gL}^{-1} \mathrm{~s}^{-1}$ \\
\hline
\end{tabular}

Reaction processes $P$ considered in C-GEM comprise aerobic degradation, denitrification, nitrification, primary production, phytoplankton mortality, and air-water gas exchange for $\mathrm{O}_{2}$ and $\mathrm{CO}_{2}$ (Fig. 4 and Table 3). These processes and their mathematical formulation are described in detail in Volta et al. (2014) and Volta et al. (2016a).

The nonlinear partial differential equations for the hydrodynamics are solved by a finite difference scheme following the approach of Regnier et al. (1997), Regnier and Steefel (1999), and Vanderborght et al. (2002). The time step $\Delta t$ is $150 \mathrm{~s}$ and the grid size $\Delta x$ is constant along the longitudinal axis of the estuary. The grid size default value is $2000 \mathrm{~m}$, but can be smaller for short-length estuaries to guarantee a minimum of 20 grid points within the computational domain. Transport and reaction terms are solved in sequence within a single time step using an operator splitting approach (Regnier et al., 1997). The advection term in the transport equation is integrated using a third-order-accurate total-variationdiminishing (TVD) algorithm with flux limiters (Regnier et al., 1998), ensuring monotonicity (Leonard, 1984), while a semi-implicit Crank-Nicholson algorithm is used for the dispersion term (Press et al., 1992). These schemes have been extensively tested using the CONTRASTE estuarine model (e.g., Regnier et al., 1998; Regnier and Steefel, 1999; Vanderborght et al., 2002) and guarantee mass conservation to within $<1 \%$. The reaction network (including erosion- deposition terms when the constituent is a solid species) is numerically integrated using the Euler method (Press et al., 1992). The primary production dynamics, which take into account the combined effects of nutrient limitation and light attenuation in the water column induced by its background turbidity and suspended particle matter (SPM) concentration, requires vertical resolution of the photic depth. The latter is calculated according to the method described in Vanderborght et al. (2007). This method assumes an exponential decrease in the light in the water column (Platt et al., 1980), which is solved using a Gamma function.

\subsection{Boundary and forcing conditions}

Boundary and forcing conditions are extracted from global databases and global model outputs that are available at $0.5^{\circ}$ resolution. Therefore, C-GEM simulations are performed at the same resolution according to the following procedure. First, 42 coastal cells corresponding to tidal estuaries are identified in the studied area (Fig. 1). If the mouth of an estuary is spread over several $0.5^{\circ}$ grid cells, those cells are regrouped in order to represent a single estuary (e.g., Delaware estuary), and subsequently, a single idealized geometry is defined as described above. The model outputs (Hartmann et al., 2009; Mayorga et al., 2010) and databases (Antonov et al., 2010; Garcia et al., 2010a, b) used to constrain our boundary conditions are representative of the year 2000.

For each resulting cell, boundary and forcing conditions are calculated for the following periods: January-March, April-June, July-September, and October-December. This allows for an explicit representation of the seasonal variability in the simulations.

\subsubsection{External forcings}

Transient physical forcings are calculated for each season and grid cell using monthly mean values of water temperature (World Ocean Atlas; Antonov et al., 2010; Locarini et al., 2010) and seasonal averaged values for wind speed (Cross-Calibrated Multi-Platform (CCMP) Ocean Surface Wind Vector Analyses project; Atlas et al., 2011). Mean daily solar radiation and photoperiods (corrected for cloud coverage using the ISCCP Cloud Data Products; Rossow and Schiffer, 1999) are calculated depending on latitude and day of the year using a simple model (Brock, 1981).

\subsubsection{Riverine discharge, concentrations, and fluxes}

River discharges are extracted from the UNH/GRDC runoff data set (Fekete et al., 2002). These discharges represent long-term averages (1960-1990) of monthly and annual runoff at $0.5^{\circ}$ resolution. The data set is a composite of long-term gauging data, which provide average runoff for the largest river basins, and a climate-driven water balance model (Fekete et al., 2002). Total runoff values are then aggregated for each watershed at the coarser $0.5^{\circ}$ resolu- 


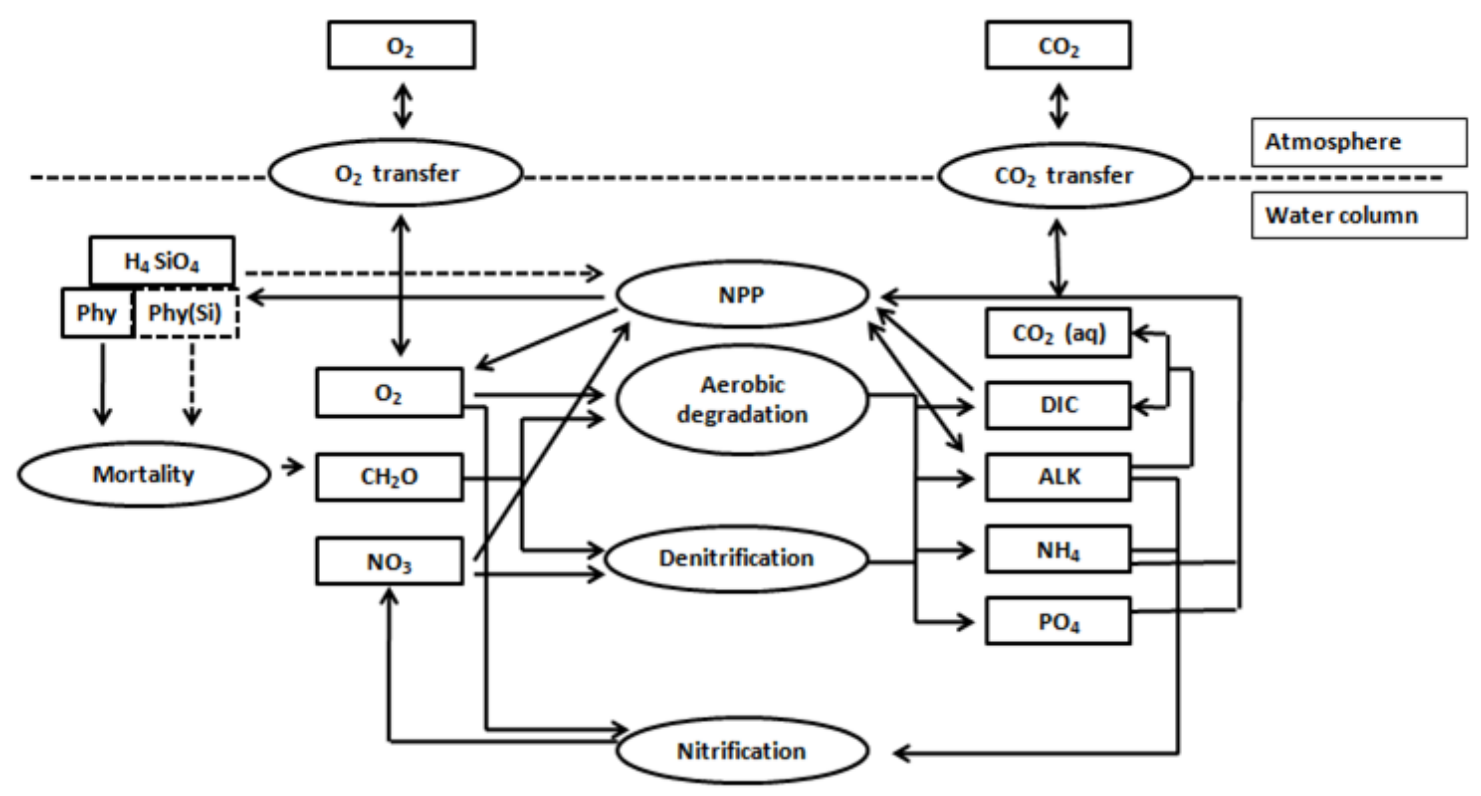

Figure 4. Conceptual scheme of the biogeochemical module of C-GEM used in this study. State variables and processes are represented by boxes and ovals, respectively. Modified from Volta et al. (2014).

tion (Fig. 3b). Next, seasonal mean values (in $\mathrm{m}^{2} \mathrm{~s}^{-1}$ ) are derived in order to account for the intra-annual variability in water fluxes. Based on annual carbon and nutrient inputs from the watersheds $\left(\mathrm{Mg} \mathrm{yr}^{-1}\right)$, mean annual concentrations $\left(\mathrm{mmol} \mathrm{m}^{-3}\right)$ are estimated for each watershed using the $\mathrm{UNH} / \mathrm{GRDC}$ annual runoff $\left(\mathrm{km}^{2} \mathrm{yr}^{-1}\right)$. Mean seasonal concentrations are then calculated from the seasonally resolved river water fluxes of a given subregion.

Annual inputs of DOC, POC, and inorganic nutrients are derived from the global NEWS2 model (Mayorga et al., 2010). Global NEWS is a spatially explicit, multielement $(\mathrm{N}, \mathrm{P}, \mathrm{Si}, \mathrm{C})$, and multi-form global model of nutrient exports from rivers. In a nutshell, DOC exports are a function of runoff, wetland area, and consumptive water use (Harrison et al., 2005). No distinction is made between agricultural and natural landscapes since they appear to have similar DOC export coefficients (Harrison et al., 2005). Sewage inputs of organic carbon (OC) are ignored in Global NEWS because their inclusion did not improve model fit to data (Harrison et al., 2005). POC exports from watersheds are estimated using an empirical relationship with SPM (Ludwig et al., 1996). Inorganic nitrogen (DIN) and phosphorus (DIP) fluxes calculated by Global NEWS depend on agriculture and tropical forest coverage, fertilizer application, animal grazing, sewage input, atmospheric $\mathrm{N}$ deposition, and biological $\mathrm{N}$ fixation (Mayorga et al., 2010). The inputs of dissolved silica (DSi) are controlled by soil bulk density, precipitation, slope, and presence of volcanic lithology (Beusen et al., 2009).

The DIN speciation is not provided by the Global NEWS2 model. The $\mathrm{NH}_{4}$ and $\mathrm{NO}_{3}$ concentrations are therefore determined independently on the basis of an empirical rela- tionship between ammonium fraction $\left(\mathrm{NH}_{4} / \mathrm{DIN}\right.$ ratio) and DIN loads (Meybeck, 1982). Dissolved oxygen (DO) concentrations are extracted from the water quality criteria recommendations published by the US Environmental Protection Agency (EPA, 2009). The same source is used for phytoplankton concentrations, using a ratio of chlorophyll $a$ to phytoplankton carbon of $50 \mathrm{~g} \mathrm{C}$ (gChla) $)^{-1}$ (Riemann et al., 1989) to convert the EPA values to carbon units used in the present study.

Inputs of DIC and total alkalinity (ALK) are calculated from values reported in the GLORICH database (Hartmann et al., 2009). For each watershed, seasonal mean values of DIC and ALK concentrations are estimated from measurements performed at the sampling locations that are closest to the river-estuary boundary. The spatial distribution of annual inputs of $\mathrm{TOC}=\mathrm{DOC}+\mathrm{POC}, \mathrm{DIC}$, and $\mathrm{TC}=\mathrm{TOC}+\mathrm{DIC}$ from continental watersheds to estuaries are reported in Fig. 5a, c, and d, respectively. The contribution of tidal wetlands to the total organic carbon (TOC) inputs is also shown (Fig. 5b). Overall, the total carbon (TC) input over the entire

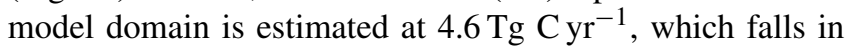
the lower end of previous reported estimations (Najjar et al., 2012).

\subsubsection{Inputs from tidal wetlands}

The DOC input of estuarine wetlands (Fig. 5b) scales to their fraction, $W$, of the total estuarine and is calculated using the 

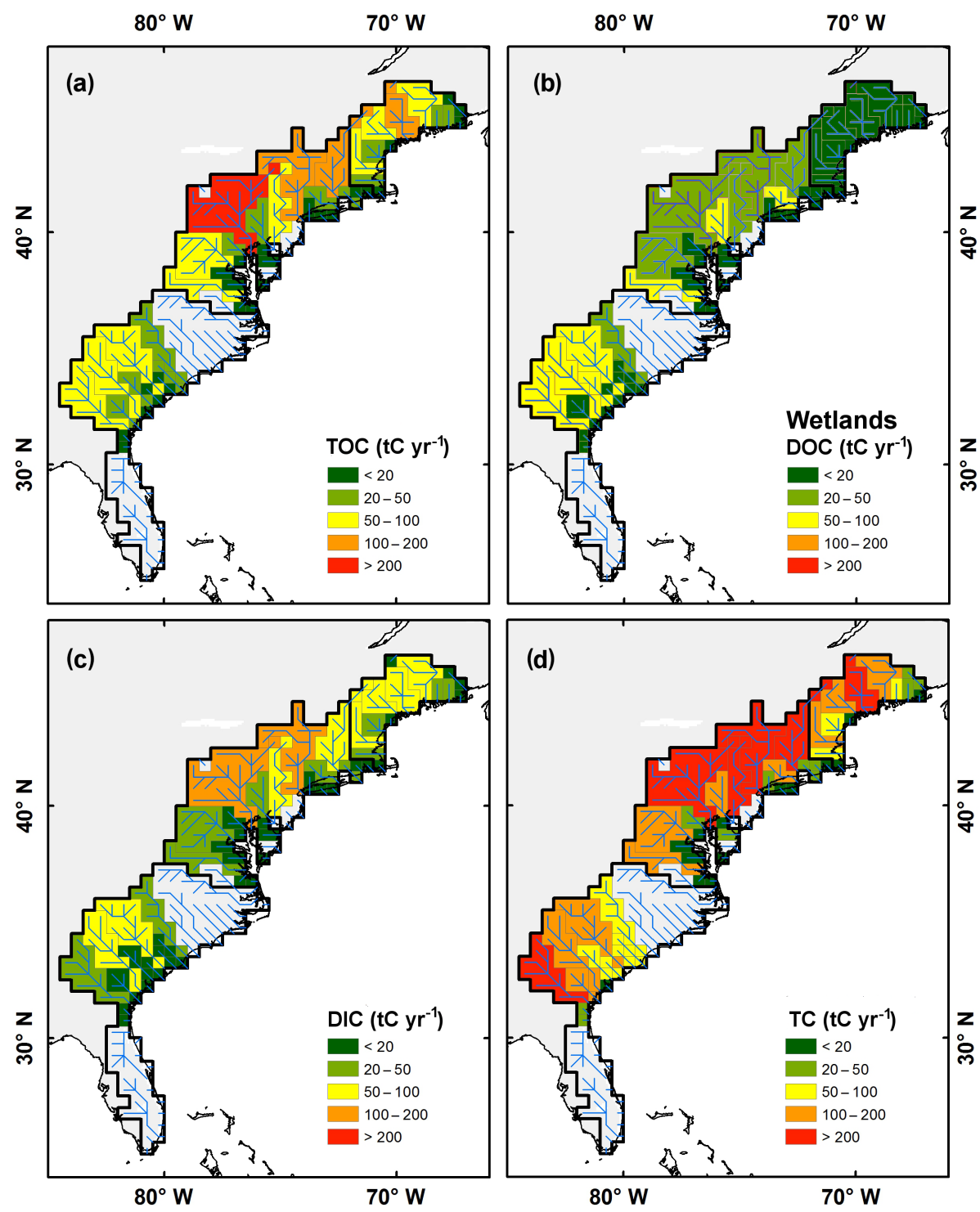

Figure 5. Annual river carbon loads of TOC (a), annual DOC fluxes from wetlands (b), annual river carbon loads of DIC (c), and annual TC fluxes (d). All fluxes are indicated per watershed.

Global NEWS parameterization.

$$
\begin{aligned}
& Y \_ \text {DOC }=\frac{\left[\left(E_{-} C_{\text {wet }} \times W\right)+E_{-} C_{\text {dry }} \times(1-W)\right] \times R^{a} \times Q_{\text {act }}}{Q_{\text {nat }}} \\
& \frac{Y \_ \text {DOC }}{Y \_ \text {wet }}=\frac{E_{-} C_{\text {wet }} \times W}{E_{-} C_{\text {wet }} * W+E_{-} C_{\text {dry }} \times(1-W)}
\end{aligned}
$$

Y_DOC is the DOC yield $\left(\mathrm{kg} \mathrm{C} \mathrm{km}^{-2} \mathrm{yr}^{-1}\right)$ calculated for the entire watershed, $\mathrm{Y}_{-} \mathrm{DOC}_{\text {wet }}$ is the estimated DOC yield from wetland areas $\left(\mathrm{kg} \mathrm{C} \mathrm{km}^{-2} \mathrm{yr}^{-1}\right), Q_{\text {act }} / Q_{\text {nat }}$ is the ratio between the measured discharge after dam construction and before dam construction, E_ $\mathrm{C}_{\mathrm{wet}}$ and E_ $\mathrm{C}_{\mathrm{dry}}$ $\left(\mathrm{kg} \mathrm{C} \mathrm{km}^{-2} \mathrm{yr}^{-1}\right.$ ) are the export coefficients of DOC from wetland and non-wetland soils, respectively. $W$ is the percentage of the land area within a watershed that is covered by wetlands, $R$ is the runoff $\left(\mathrm{m} \mathrm{yr}^{-1}\right)$, and $a$ is a unit-less calibration coefficient defining how non-point source DOC export responds to runoff. The value of $a$ is set to 0.95 , consistent with the original Global NEWS-DOC model of Harrison et al. (2005). The carbon load Y_DOC ${ }_{w e t}$ is then exported as a diffuse source along the relevant portions of estuary. The estuarine segments receiving carbon inputs from tidal wetlands are identified using the National Wetlands Inventory of the US Fish and Wildlife Service (US Fish and Wildlife Service, 2014). The inputs from those systems are then allocated to the appropriate grid cell of the model domain using a GIS. The flux calculated is an annual average that is subsequently partitioned between the four seasons as a function of the mean seasonal temperature, assumed to be the main control of the wetland-estuarine exchange. This procedure reflects the observation that in spring and early 
summer, DOC export is low as a result of its accumulation in the salt marshes induced by high productivity (Dai and Wiegert, 1996), (Jiang et al., 2008). In late summer and fall, the higher water temperature and greater availability of labile DOC contribute to higher bacterial remineralization rates in the intertidal marshes (Cai et al., 1999; Middelburg et al., 1996; Wang and Cai, 2004), which induce an important export. This marsh production-recycle-export pattern is consistent with the observed excess DIC signal in the offshore water (Jiang et al., 2013). DIC export from tidal wetlands is neglected here because it is assumed that OC is not degraded before reaching the estuarine realm. Although this assumption may lead to an overestimation of OC export from marshes and respiration in estuarine water, it will not significantly affect the water $p \mathrm{CO}_{2}$ and degassing in the estuarine waters because mixing is faster than respiration.

\subsubsection{Concentrations at the estuarine mouth}

For each estuary, the downstream boundary is located $20 \mathrm{~km}$ beyond the mouth to minimize the bias introduced by the choice of a fixed concentration boundary condition to characterize the ocean water masses (e.g., Regnier et al., 1998). This approach also reduces the influence of marine boundary conditions on the simulated estuarine dynamics, especially for all organic carbon species whose concentrations are fixed at zero at the marine boundary. This assumption ignores the intrusion of marine organic carbon into the estuary during the tidal cycle but allows a focus on the fate of terrigenous material and its transit through the estuarine filter. DIC concentrations are extracted from the GLODAP data set (Key et al., 2004), from which ALK and pH are calculated assuming $\mathrm{CO}_{2}$ equilibrium between coastal waters and the atmosphere. The equilibrium value is computed using temperature (WOA2009; Locarnini et al., 2010) and salinity (WOA2009; Antonov et al., 2010) data, which vary both spatially and temporally. The equilibrium approach is a reasonable assumption because differences in partial pressure $\Delta p \mathrm{CO}_{2}$ between coastal waters and the atmosphere are generally much smaller (0-250 $\mu$ atm; Signorini et al., 2013) than those reported for estuaries $\left(\Delta p \mathrm{CO}_{2}\right.$ in the range 0 $10000 \mu \mathrm{atm}$; Borges and Abril, 2012). Salinity, DO, $\mathrm{NO}_{3}$, DIP, and DSi concentrations are derived from the World Ocean Atlas (Antonov et al., 2010; Garcia et al., 2010a, b). $\mathrm{NH}_{4}$ concentrations are set to zero in marine waters. For all variables, seasonal means are calculated for each grid cell of the boundary.

\subsection{Biogeochemical indicators}

The model outputs (longitudinal profiles of concentration and reaction rates) are integrated in time over the entire volume or surface of each estuary to produce the following indicators of the estuarine biogeochemical functioning (Regnier et al., 2013b): the mean annual NEM, the air-water $\mathrm{CO}_{2}$ flux $\left(\mathrm{FCO}_{2}\right)$, the carbon and nitrogen filtering capacities (CFilt and NFilt), and their corresponding element budgets. The NEM (molC yr ${ }^{-1}$ ) (Caffrey, 2004; Odum, 1956) is defined as the difference between net primary production (NPP) and total heterotrophic respiration (HR) on the system scale.

$$
\begin{aligned}
\mathrm{NEM} & =\int_{0}^{365} \int_{0}^{L}\left[\mathrm{NPP}(x, t)-R_{\mathrm{aer}}(x, t)-R_{\mathrm{den}}(x, t)\right] \\
& \times B(x) \times H(x, t) \mathrm{d} x \mathrm{~d} t
\end{aligned}
$$

NPP is in mol $\left.\mathrm{C} \mathrm{m}^{-3} \mathrm{yr}^{-1}\right), R_{\mathrm{aer}}$ is the aerobic degradation of organic matter (in mol $\mathrm{C} \mathrm{m}^{-3} \mathrm{yr}^{-1}$ ), and $R_{\mathrm{den}}$ is the denitrification (in mol C m${ }^{-3} \mathrm{yr}^{-1}$ ) (see Volta et al., 2014, for detailed formulations). NEM is thus controlled by the production and decomposition of autochthonous organic matter, by the amount and degradability of organic carbon delivered by rivers and tidal wetlands, and by the export of terrestrial and in-situ-produced organic matter to the adjacent coastal zone. Following the definition of NEM, the trophic status of estuaries can be net heterotrophic $(\mathrm{NEM}<0)$, when HR exceeds NPP, or net autotrophic (NEM $>0)$, when NPP is larger than HR because the burial and export of autochthonous organic matter exceeds the decomposition of river-borne material.

The $\mathrm{FCO}_{2}\left(\mathrm{~mol} \mathrm{C} \mathrm{yr}^{-1}\right)$ is defined as the following.

$$
\begin{aligned}
& \mathrm{FCO}_{2}=\int_{0}^{365} \int_{0}^{L} \mathrm{RCO}_{2}(x, t) * B(x) \mathrm{d} x \mathrm{~d} t \\
& \mathrm{RCO}_{2}(x t)=-v_{\mathrm{p}}(x, t)\left(\left[\mathrm{CO}_{2(\mathrm{aq})}\right](x, t)\right. \\
& \left.-K_{0}(x, t) \times P_{\mathrm{CO}_{2}}(x, t)\right)
\end{aligned}
$$

$\mathrm{RCO}_{2}\left(\mathrm{molC} \mathrm{m}^{-2} \mathrm{yr}^{-1}\right)$ is the rate of exchange in $\mathrm{CO}_{2}$ at the air-water interface per unit surface area. $v_{\mathrm{p}}$ is the piston velocity $\left(\mathrm{m} \mathrm{yr}^{-1}\right)$ and is calculated according to Regnier et al. (2002) to account for the effect of current velocity and wind speed, $\left[\mathrm{CO}_{2}(\mathrm{aq})\right]$ is the concentration of $\mathrm{CO}_{2}$ in the estuary $\left(\mathrm{mol} \mathrm{m}{ }^{-3}\right), K_{0}$ is Henry's constant of $\mathrm{CO}_{2}$ in seawater $\left(\mathrm{mol} \mathrm{m}^{-3} \mathrm{~atm}^{-1}\right)$, and $P_{\mathrm{CO}_{2}}$ is the atmospheric partial pressure in $\mathrm{CO}_{2}$ (atm).

The carbon-filtering capacity (as a percentage) corresponds to the fraction of the river-borne supply that is lost to the atmosphere and is defined here as the ratio of the net outgassing flux of $\mathrm{CO}_{2}$ and the total inputs of $\mathrm{C}$, e.g., total carbon expressed as the sum of inorganic and organic carbon 


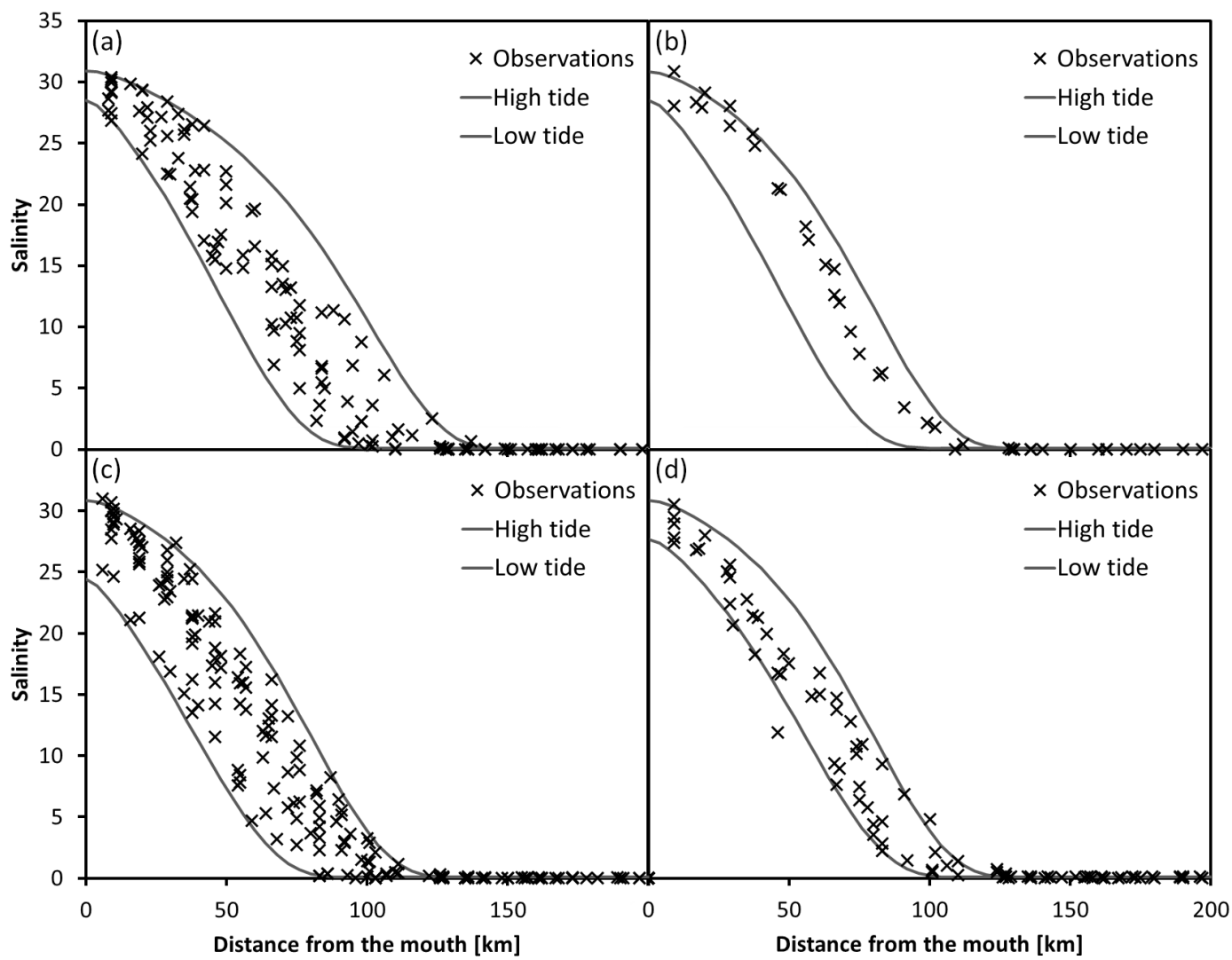

Figure 6. Modeled (lines) and measured (crosses) salinities in the Delaware Bay estuary for January (a), February (b), May (c), and June (d). The two lines correspond to high and low tides.

species, both in the dissolved and particulate phases.

$$
\text { CFilt }=\frac{\mathrm{FCO}_{2}}{\int_{0}^{365} Q \times[\mathrm{TC}]_{\text {riv }} \mathrm{d} t} \times 100
$$

$[\mathrm{TC}]_{\mathrm{riv}}$ denotes the total concentration of $\mathrm{C}$ in each riverine input.

Fluxes per unit area for $\mathrm{FCO}_{2}$ and NEM, denoted as $\overline{\mathrm{FCO}_{2}}$ and $\overline{\mathrm{NEM}}$, respectively, are defined in mol $\mathrm{C} \mathrm{m}^{-2} \mathrm{yr}^{-1}$ and are calculated by dividing the integrated values calculated above by the (idealized) estuarine surface $S$.

$\overline{\mathrm{NEM}}=\frac{\mathrm{NEM}}{S} \times 1000$

$\overline{\mathrm{FCO}}_{2}=\frac{\mathrm{FCO}_{2}}{S} \times 1000$

Seasonal values for the biogeochemical indicators are calculated using the same formula as above, but calculating the integral over a seasonal rather than annual timescale (i.e., 3 months).

\subsection{Model-data comparison}

C-GEM has been specifically designed for an application on a global and/or regional scale, requiring the representation of a large number of individual and often data-poor systems. Maximum model transferability and minimum validation requirements were thus central to the model design process and the ability of the underlying approach to reproduce observed dynamics with minimal calibration effort has been extensively tested. The performance C-GEM's one-dimensional hydrodynamic and transport models using idealized geometries have been evaluated for a number of estuarine systems exhibiting a wide variety of shapes (Savenije, 2012). In particular, it has been shown that the estuarine salt intrusion can be successfully reproduced using the proposed modeling approach (Savenije 2005; Volta et al., 2014, 2016b). In addition, C-GEM's biogeochemistry has also been carefully validated for geometrically contrasting estuarine systems in temperate climate zones. Simulations for the Scheldt Estuary (Belgium and the Netherlands), a typical funnel-shaped estuary, were validated through model-data and model-model comparisons (Volta et al., 2014, 2016a). Furthermore, simulations for the Elbe estuary (Germany), a typical prismatic shape estuary that drains carbonate terrains and thus exhibits very high $\mathrm{pH}$, was validated against field data (Volta et al., 2016a). In addition, carbon budgets calculated using C-GEM for six European estuaries discharging in the North Sea have been compared with budgets derived from observations (Volta et 
al., 2016a). Although C-GEM has been specifically designed and tested for the type of regional application presented here, its transferability from North Sea to US East Coast estuaries was further evaluated by assessing its performance in two US East Coast estuaries. First, the hydrodynamic and transport model was tested for the Delaware Bay (MAR). The model was forced with the monthly, minimal, and maximal observed discharges at Trenton over the period between 1912 and 1985 (UNH/GRDC database; GRDC, 2014). Simulated salinity profiles are compared with salinity observations (the months with the highest number of data entries), which were extracted from the UNH/GRDC database from January, February, May, and June. Figure 6 shows that the model captures both the salinity intrusion length and the overall shape of the salinity profile well. In addition, the performance of the biogeochemical model and specifically its ability to reproduce $\mathrm{pH}$ and $p \mathrm{CO}_{2}$ profiles was evaluated by a model-data comparison for both the Delaware Bay (MAR) in July 2003 and the Altamaha River estuary (SAR) in October 1995. Similar to Volta et al. (2016a), the test systems were chosen due to their contrasting geometries. The Delaware Bay is a marine-dominated system characterized by a pronounced funnel shape, while the Altamaha River has a prismatic estuary characteristic of river-dominated systems (Jiang et al., 2008). Monthly upstream boundary conditions for nutrients, as well as observed $\mathrm{pH}$ data and calculated $p \mathrm{CO}_{2}$ are extracted from data sets described in Sharp (2010) and Sharp et al. (2009) for the Delaware and in Cai and Wang (1998), Jiang et al. (2008), and Cai et al. (1998) for the Altamaha River estuary. The additional forcings and boundary conditions are set similarly to the simulation for 2000 (see Tables S2, S3, S4, S5, and S6 in the Supplement). Figure 7 shows that measured and simulated $\mathrm{pH}$ values are in good agreement with observed $\mathrm{pH}$ and observation-derived calculations of $p \mathrm{CO}_{2}$. In the Delaware Bay, a $\mathrm{pH}$ minimum is located around $140 \mathrm{~km}$ and is mainly caused by intense nitrification sustained by large inputs of $\mathrm{NH}_{4}$ from the Philadelphia urban area, coupled to an intense heterotrophic activity. Both processes lead to a well-developed $p \mathrm{CO}_{2}$ increase in this area (Fig. 7c). Overall, the longitudinal $p \mathrm{CO}_{2}$ profile of the Delaware estuary is characterized by values close to equilibrium with the atmosphere in the widest section of the Delaware Bay (near the estuarine mouth and throughout the first $40 \mathrm{~km}$ of the system), with values above $1200 \mu \mathrm{atm}$ at $150 \mathrm{~km}$ and beyond, where characteristic salinities are below 5. Although the profile presented here is simulated using boundary conditions representative of July 2003 and no $p \mathrm{CO}_{2}$ data were available for validation for this period, a recent study by Joesoef et al. (2015) reports a similar longitudinal $p \mathrm{CO}_{2}$ profile in July 2013. For the Altamaha River estuary, $\mathrm{pH}$ steadily increases from typical river to typical coastal ocean values (Fig. 7b). In addition, both observations and model results reveal that outgassing is very intense in the low-salinity region, with more than a 5 -fold decrease in $p \mathrm{CO}_{2}$ between a salinity of 0 and 5 (Fig. $7 \mathrm{~d}$ ).
While such local validations allow the assessment of the performance of the model for a specific set of conditions, the purpose of this study is to capture the average biogeochemical behavior of the estuaries of the US East Coast. Therefore, in addition to the system-specific validation, published annually averaged $\mathrm{FCO}_{2}$ estimates for 12 tidal systems located within the study area collected over the 1994-2006 period are compared to simulated $\mathrm{FCO}_{2}$ for conditions representative of the year 2000. Overall, simulated $\mathrm{FCO}_{2}$ values are comparable to values reported in the literature (Table 2). Although significant discrepancies are observed at the level of individual systems, the model captures the overall behaviors of estuaries along the US East Coast in terms of intensity of $\mathrm{CO}_{2}$ evasion rate remarkably well. The model simulates low $\mathrm{CO}_{2}$ efflux $\left(<5 \mathrm{~mol} \mathrm{C} \mathrm{m}^{-2} \mathrm{yr}^{-1}\right)$ for the six systems where such conditions have been observed, while the five systems for which the $\mathrm{CO}_{2}$ evasion exceeds $10 \mathrm{~mol} \mathrm{C} \mathrm{m}^{-2} \mathrm{yr}^{-1}$ are the same in the observations and in the model runs. The discrepancies at the individual system level likely result from a combination of factors, including the choice of model processes and their parametrization, the uncertainties in constraining boundary conditions, and the limited representability of instantaneous and local observations.

\section{Results and discussion}

\subsection{Spatial variability of estuarine carbon dynamics}

Figure 8 presents the spatial distribution of simulated mean annual $\overline{\mathrm{FCO}}_{2}$ and $-\overline{\mathrm{NEM}}$ (Fig. 8a), as well as $\mathrm{FCO}_{2}$ and -NEM (Fig. 8b). In general, mean annual $\overline{\mathrm{FCO}}_{2}$ values are about $30 \%$ larger than mean annual $\overline{\mathrm{NEM}}$ values, with the exception of six estuaries situated in the north of the coastal segment. Overall, the $\overline{\mathrm{NEM}}$ is characterized by smaller system-to-system variability compared to the $\overline{\mathrm{FCO}}_{2}$ in all regions. In addition, Fig. 8 reveals distinct differences across the three coastal segments and highlights the important influence of the estuarine geometry and residence time, as well as the latitudinal temperature gradient on estuarine carbon cycling.

Overall, $\overline{\mathrm{FCO}}_{2}$ values are the lowest in the NAR (mean flux $=17.3 \pm 16.4 \mathrm{~mol} \mathrm{C} \mathrm{m}^{-2} \mathrm{yr}^{-1}$; surface-weighted average $=23.1 \mathrm{~mol} \mathrm{C} \mathrm{m}^{-2} \mathrm{yr}^{-1}$ ), consistent with previously reported very low values for small estuaries surrounding the Gulf of Maine (Hunt et al., 2010, 2011; Table 2). In contrast, $\overline{\mathrm{NEM}}$ reveals a regional minimum in the NAR $\left(-51.2 \pm 16.6 \mathrm{~mol} \mathrm{C} \mathrm{m}^{-2} \mathrm{yr}^{-1}\right.$; surface-weighted average $\left.=-52.8 \mathrm{~mol} \mathrm{C} \mathrm{m}^{-2} \mathrm{yr}^{-1}\right)$. The MAR is characterized by intermediate values for $\overline{\mathrm{FCO}}_{2}$, with a mean flux of $26.3 \pm 34.6 \mathrm{~mol} \mathrm{C} \mathrm{m}^{-2} \mathrm{yr}^{-1}$ (surface-weighted average $=11.1 \mathrm{~mol} \mathrm{C} \mathrm{m}^{-2} \mathrm{yr}^{-1}$ ) and the lowest values for $\overline{\mathrm{NEM}}\left(-15.1 \pm 14.2 \mathrm{~mol} \mathrm{C} \mathrm{m}^{-2} \mathrm{yr}^{-1}\right.$; surface-weighted average $\left.=-7.4 \mathrm{~mol} \mathrm{C} \mathrm{m}^{-2} \mathrm{yr}^{-1}\right)$. This region also shows the largest variability in $\mathrm{CO}_{2}$ outgassing compared to the 

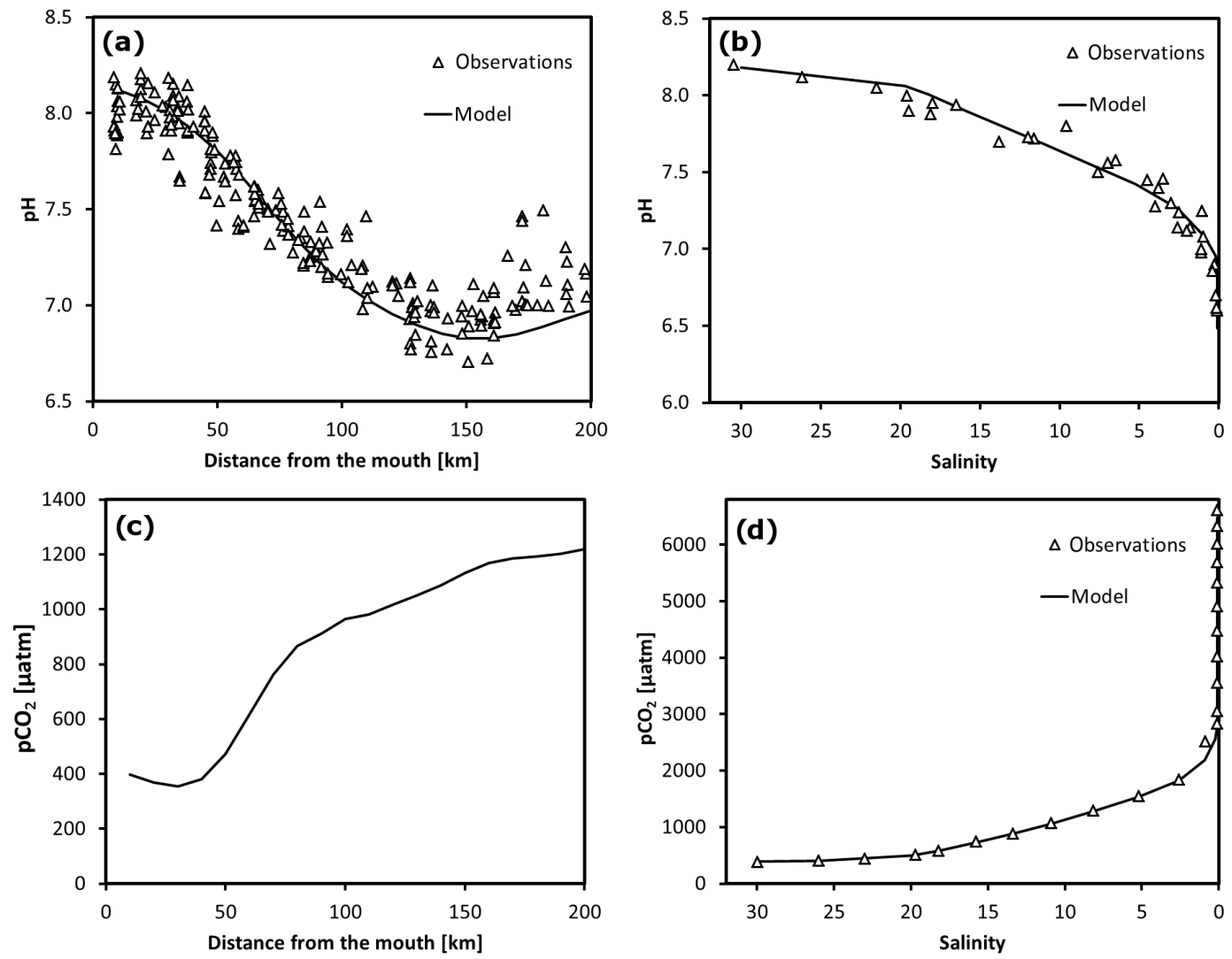

Figure 7. Longitudinal profiles of $\mathrm{pH}$ (top) and $p \mathrm{CO}_{2}$ (bottom) for the Delaware Bay (left) and Altamaha River estuary (right).
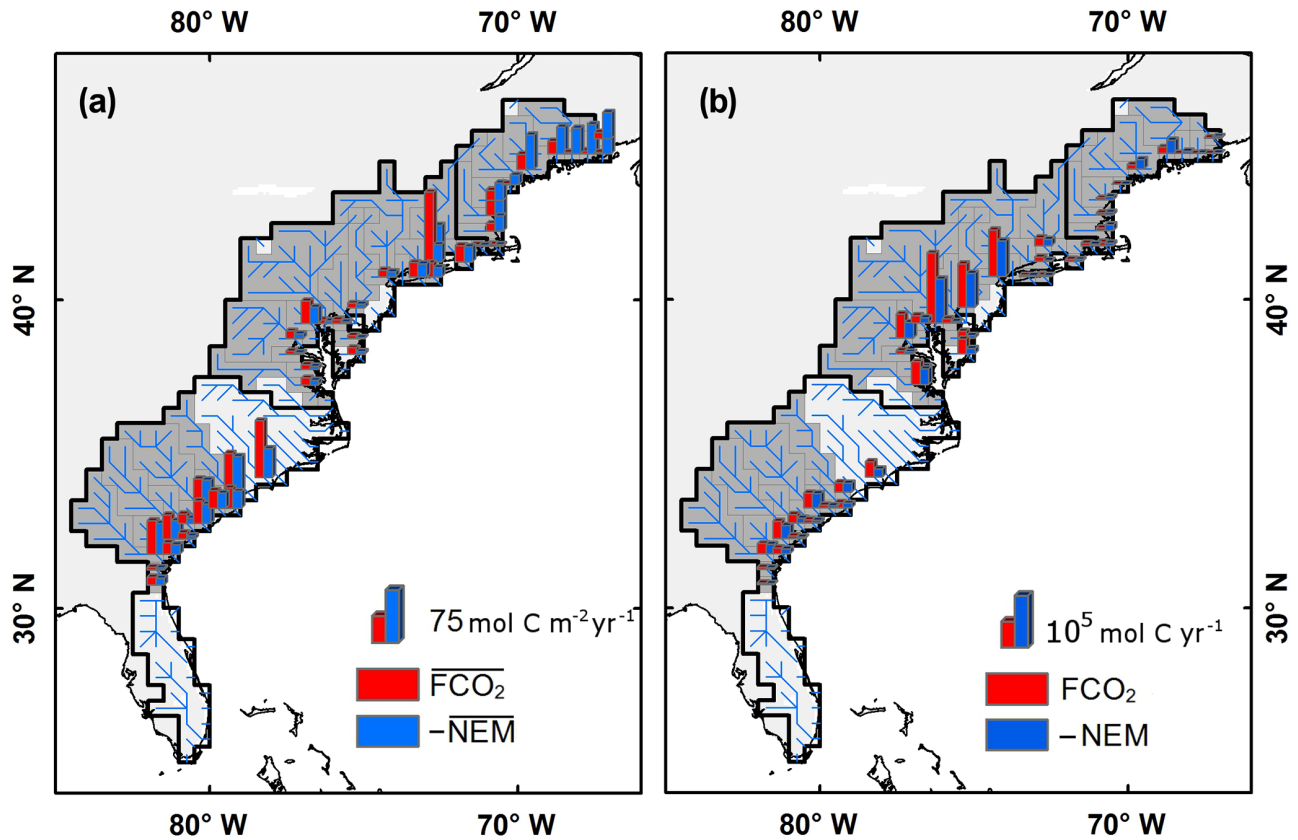

Figure 8. Spatial distribution of spatially averaged value (a) and integrated value (b) of mean annual $\mathrm{FCO}_{2}$ (red) and $-\mathrm{NEM}$ (blue) along the US East Coast. In panel (a), the notation with over bars $\left(\overline{\mathrm{FCO}}_{2}\right.$ and $\left.-\overline{\mathrm{NEM}}\right)$ represents rates per unit surface. For the sake of the comparison with $\overline{\mathrm{FCO}}_{2}$, Fig. 8 displays $-\overline{\mathrm{NEM}}$ because the model predicts that all estuaries in this region are net heterotrophic. 
NAR and SAR, with the standard deviation exceeding the mean $\overline{\mathrm{FCO}}_{2}$, and individual estimates ranging from 3.9 to $150.8 \mathrm{~mol} \mathrm{C} \mathrm{m}^{-2} \mathrm{yr}^{-1}$. This variability is mainly the result of largely variable estuarine surface areas and volumes. Some of the largest US East Coast estuaries (e.g., Chesapeake and Delaware bays), as well as some of smallest estuaries (e.g., York River and Hudson River estuaries; Raymond et al., 1997, 2000), are located in this region (Tables 2 and 4). The maximum value of $150.8 \mathrm{~mol} \mathrm{C} \mathrm{m}^{-2} \mathrm{yr}^{-1}$ simulated in the MAR is similar to the highest $\mathrm{FCO}_{2}$ value reported in the literature $\left(132.3 \mathrm{~mol} \mathrm{C} \mathrm{m}^{-2} \mathrm{yr}^{-1}\right.$ for the Tapti estuary in India; Sarma et al., 2012). The SAR is characterized by the

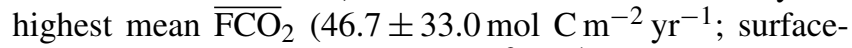
weighted average $=40.0 \mathrm{~mol} \mathrm{C} \mathrm{m}^{-2} \mathrm{yr}^{-1}$ ) and intermediate $\overline{\mathrm{NEM}}\left(-36.8 \pm 24.7 \mathrm{~mol} \mathrm{C} \mathrm{m}^{-2} \mathrm{yr}^{-1}\right.$; surface-weighted average $\left.=-31.2 \mathrm{~mol} \mathrm{C} \mathrm{m}^{-2} \mathrm{yr}^{-1}\right)$.

The NAR is characterized by a regional minimum in $\overline{\mathrm{FCO}}_{2}$ and only contributes $4.6 \%$ to the total $\mathrm{FCO}_{2}$ of the US East Coast, owing to the small cumulative surface area available for gas exchange in its 10 estuarine systems. In contrast, the 18 MAR estuaries, with their large relative contribution to the total regional estuarine surface area, account for as much as $70.1 \%$ of the total outgassing. Because of their smaller cumulated surface area compared to those of the MAR, the 14 SAR estuaries account for merely $25.3 \%$ of the total outgassing despite their regional maximal $\overline{\mathrm{FCO}}_{2}$. A similar, yet slightly less pronounced pattern emerges for the $\overline{\mathrm{NEM}}$. The NAR, MAR, and SAR respectively contribute $13.7,60.7$, and $25.6 \%$ to the total regional net ecosystem metabolism. The comparatively larger relative contribution of the NAR to the total NEM as compared to the total $\mathrm{FCO}_{2}$ can be explained by the importance of the specific aspect ratio for NEM. A larger ratio of estuarine width $\mathrm{B} 0$ and convergence length $\mathrm{b}$ corresponds to a more funnel-shaped estuary, while a low ratio corresponds to a more prismatic geometry (Savenije, 2005; Volta et al., 2014). In the NAR, estuaries are generally characterized by relatively narrow widths and deepwater depths, thus limiting the potential surface area for gas exchange with the atmosphere. However, the relative contribution of each region to the total regional NEM and $\mathrm{FCO}_{2}$ is largely controlled by estuarine surface area. Figure 9 illustrates the cumulative $\mathrm{FCO}_{2}$ (a) and NEM (b) as a function of the cumulative estuarine surface areas. The disproportionate contribution of large estuaries from the MAR translates into a handful of systems (Chesapeake and Delaware bays and the main tributaries of the former, in particular) contributing to roughly half of the regional NEM and $\mathrm{FCO}_{2}$, in spite of relatively low individual rates per unit surface area. However, the smallest systems (mostly located in the NAR and SAR) nevertheless contribute a significant fraction to the total regional NEM and $\mathrm{FCO}_{2}$. The 27 smallest systems merely account for less than $10 \%$ of the total regional estuarine surface area, yet contribute 38 and $29 \%$ to the total regional $\mathrm{NEM}$ and $\mathrm{FCO}_{2}$, respectively (Fig. 9). This disproportional contribution can be mainly attributed to their high individ-

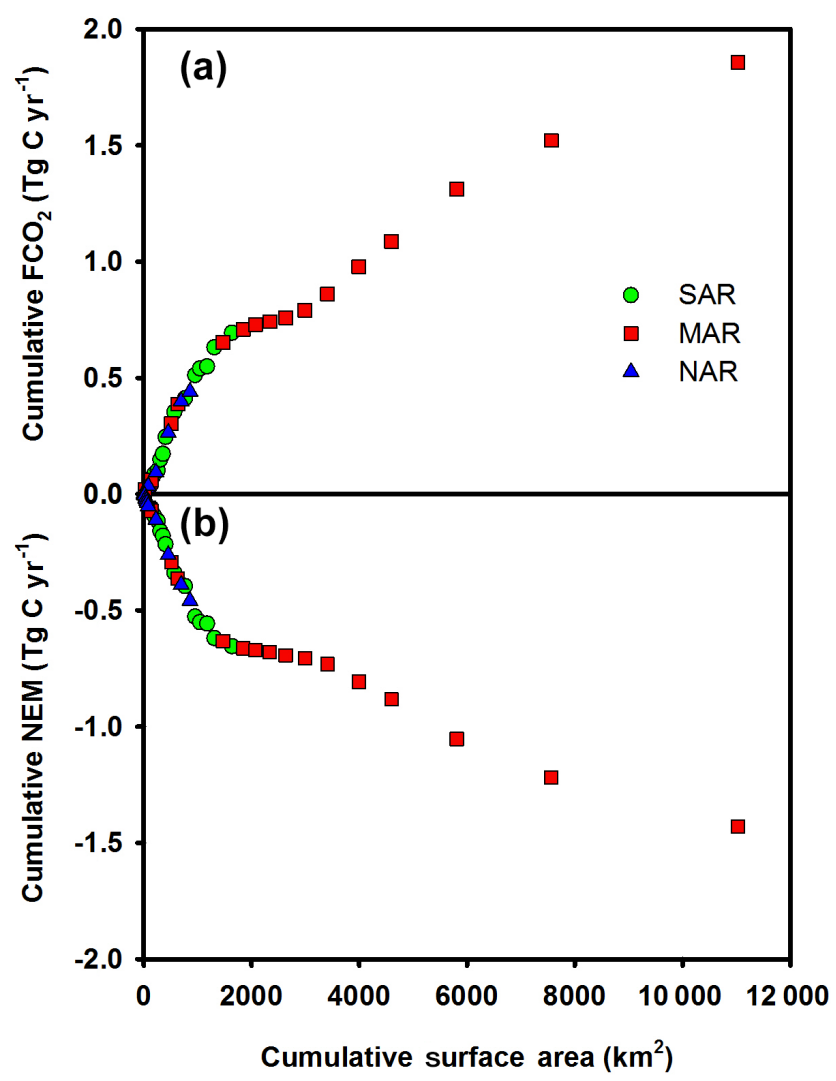

Figure 9. The cumulative $\mathrm{FCO}_{2}$ (a) and NEM (b) as functions of the cumulative estuarine surface area. Systems are sorted by increasing surface area.

ual $\overline{\mathrm{FCO}}_{2}$ and $\overline{\mathrm{NEM}}$ values. This is illustrated by the average simulated $\overline{\mathrm{FCO}}_{2}$ for all 27 smallest systems (calculated as the sum of each estuarine $\mathrm{CO}_{2}$ outgassing per unit surface area divided by the total number of estuarine systems), which is significantly higher $\left(30.2 \mathrm{~mol} \mathrm{C} \mathrm{m}^{-2} \mathrm{yr}^{-1}\right)$ than its surface-weighted average $\left(14 \mathrm{~mol} \mathrm{C} \mathrm{m}^{-2} \mathrm{yr}^{-1}\right)$. This therefore accounts for the disproportionate contribution of very large systems (calculated as the sum of each estuarine $\mathrm{CO}_{2}$ outgassing divided by the total estuarine surface area across the region).

Following the approach used in Regnier et al. (2013b), the contribution of each biogeochemical process to $\mathrm{FCO}_{2}$ is assessed by evaluating their individual contribution to DIC and ALK changes, taking into account the local buffering capacity of an ionic solution when TA and DIC are changing due to internal processes, but ignoring advection and mixing (Zeebe and Wolf-Gladrow 2001). In the present study, we quantify the effect of the NEM on the $\mathrm{CO}_{2}$ balance, which is almost exclusively controlled by aerobic degradation rates because the contributions of denitrification and NPP to the net ecosystem balance are small. Nitrification, a process triggered by the transport and/or production of $\mathrm{NH}_{4}$ in oxygenated waters, favors outgassing through its effect on $\mathrm{pH}$, which shifts the 

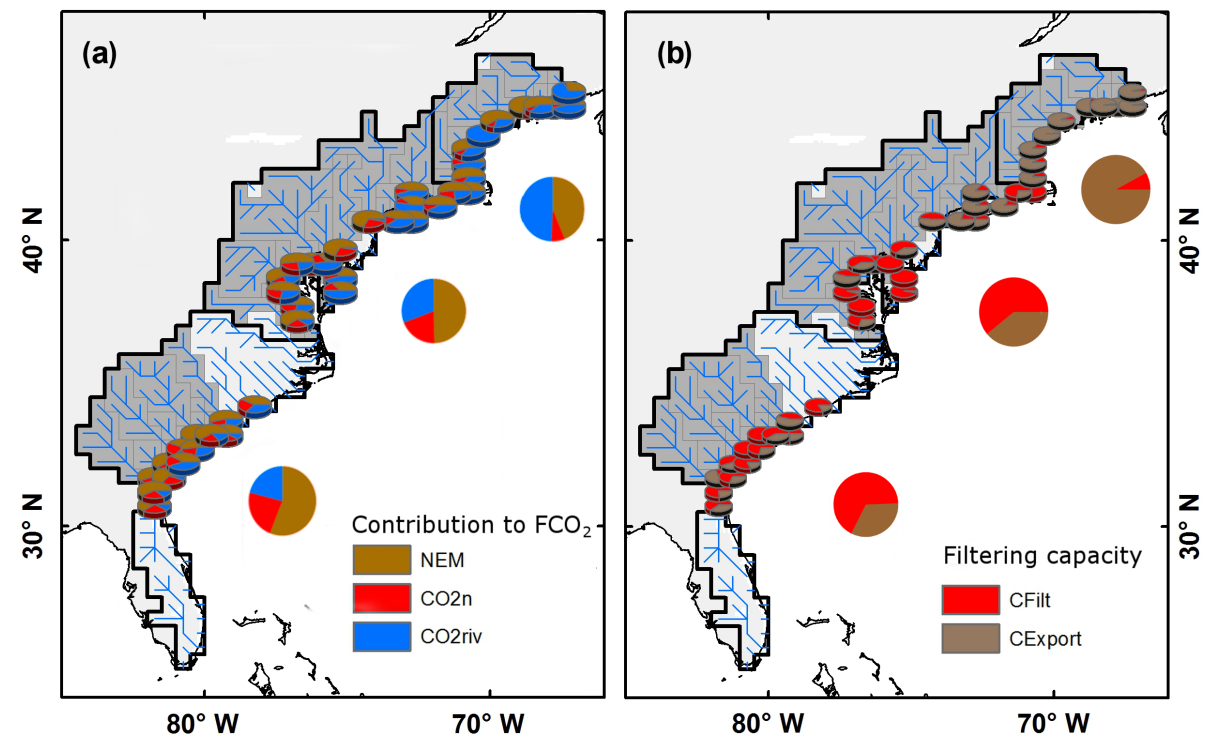

Figure 10. Contribution of NEM, nitrification, and supersaturated riverine waters to the mean annual $\mathrm{FCO}_{2}$ (a). Spatial distribution of mean annual carbon filtration capacities (CFilt) and export (CExport) along the US East Coast (b).

acid-base equilibrium of carbonate species and increases the $\mathrm{CO}_{2}$ concentration. The contribution of supersaturated riverine waters to the overall estuarine $\mathrm{CO}_{2}$ dynamics is calculated as the difference between all the other processes creating or consuming $\mathrm{CO}_{2}$. Figure 10a presents the contribution of the annually integrated NEM, nitrification, and evasion of supersaturated, DIC-enriched riverine waters to the total outgassing for each system, as well as for individual regions of the domain. The calculation of these annual values is based on the sum of the seasonal fluxes. Model results reveal that, regionally, the NEM supports about $50 \%$ of the estuarine $\mathrm{CO}_{2}$ outgassing, while nitrification and riverine DIC inputs sustain about 17 and $33 \%$ of the $\mathrm{CO}_{2}$ emissions, respectively. The relative significance of the three processes described above shows important spatial variability. In the NAR, oversaturated riverine waters and NEM respectively sustain 50 and $44 \%$ of the outgassing within the subregion, while nitrification is of minor importance (6\%). In the MAR, the contribution of riverine DIC inputs is significantly lower $(\sim 30 \%)$ and the main contribution to the outgassing is NEM ( $\sim 50 \%$ ); nitrification accounts for slightly less than $20 \%$ of the outgassing. In the SAR, the riverine contribution is even lower $(\sim 20 \%)$, and the outgassing is mainly attributed to the NEM $(\sim 55 \%)$ and nitrification $(\sim 25 \%)$. Therefore, although the model results reveal significant variability across individual systems, a clear latitudinal trend in the contribution to the total $\mathrm{FCO}_{2}$ emerges from the analysis. The importance of oversaturated riverine water decreases from north to south, while NEM and nitrification increase along the same latitudinal gradient. The increasing relative importance of estuarine biogeochemical processes over riverine DIC inputs as drivers of $\mathrm{FCO}_{2}$ along the north-south gradient is largely driven by increasing temperatures from north to south, especially in the SAR region (Table S1).

Contrasting patterns across the three regions can also be observed with respect to carbon-filtering capacities, CFilt (Fig. 10b). In the NAR, over $90 \%$ of the riverine carbon flux is exported to the coastal ocean. However, in the MAR, the high efficiency of the largest systems in processing organic carbon results in a regional CFilt that exceeds $50 \%$. This contrast between the NAR and the MAR and its potential implication for the carbon dynamics of the adjacent continental shelf waters has already been discussed by Laruelle et al. (2015). In the NAR, short estuarine residence results in a much lower removal of riverine carbon by degassing compared to the MAR. Laruelle et al. (2015) suggested that this process could contribute to the weaker continental shelf carbon sink adjacent to the NAR, compared to the MAR. In the SAR, most estuaries remove between 40 and $65 \%$ of the carbon inputs. The high temperatures observed and the resulting accelerated biogeochemical process rates in this region favor the degradation of organic matter and contribute to the increase in the estuarine capacity for filtering carbon. However, in the SAR, a large fraction of the OC loads is derived from adjacent salt marshes located along the estuarine salinity gradients, thereby reducing the overall residence time of OC within the systems. The filtering capacity of the riverine OC alone, which transits through the entire estuary, would thus be higher than the one calculated here. As a consequence, the highest $\mathrm{C}$ retention rates are expected in warm tidal estuaries devoid of salt marshes or mangroves (Cai, 2011). 
Table 4. Yearly averaged surface area $(S)$, freshwater discharge $(Q)$, residence time (Rt), $\mathrm{FCO}_{2}$, and NEM of all simulated estuaries.

\begin{tabular}{|c|c|c|c|c|c|c|c|c|}
\hline $\begin{array}{l}\text { Long } \\
\circ\end{array}$ & $\begin{array}{c}\text { Lat } \\
\circ\end{array}$ & $\begin{array}{r}S \\
\mathrm{~km}^{2}\end{array}$ & $\mathrm{~m}^{3} \mathrm{~s}^{-1}$ & $\begin{array}{r}\text { Rt } \\
\text { days }\end{array}$ & $\begin{array}{r}\overline{\mathrm{FCO}}_{2} \\
\mathrm{~mol} \mathrm{C} \mathrm{m}{ }^{-2} \mathrm{yr}^{-1}\end{array}$ & $\begin{array}{r}\overline{\mathrm{NEM}} \\
\mathrm{mol} \mathrm{C} \mathrm{m}^{-2} \mathrm{yr}^{-1}\end{array}$ & $\begin{array}{r}\mathrm{FCO}_{2} \\
10^{6} \mathrm{~mol} \mathrm{C} \mathrm{yr}^{-1}\end{array}$ & $\begin{array}{r}\text { NEM } \\
10^{6} \mathrm{~mol} \mathrm{C} \mathrm{yr}^{-1}\end{array}$ \\
\hline \multicolumn{9}{|l|}{ NAR } \\
\hline-67.25 & 44.75 & 7 & 38.5 & 15 & 3.7 & -37.4 & 27 & -270 \\
\hline-67.25 & 45.25 & 12 & 73.6 & 15 & 6.0 & -56.7 & 71 & -666 \\
\hline-67.25 & 45.25 & 12 & 73.6 & 15 & 13.8 & -56.6 & 162 & -666 \\
\hline-67.75 & 44.75 & 3 & 68.5 & 4 & 6.7 & -63.5 & 23 & -221 \\
\hline-68.25 & 44.75 & 14 & 69.5 & 19 & 4.1 & -56.2 & 58 & -791 \\
\hline-68.75 & 44.75 & 89 & 309.9 & 23 & 27.4 & -58.2 & 2431 & -5163 \\
\hline-69.75 & 44.25 & 50 & 626.6 & 5 & 32.3 & -74.4 & 1607 & -3703 \\
\hline-70.25 & 43.75 & 3 & 25.8 & 10 & 2.1 & -21.0 & 7 & -71 \\
\hline-70.75 & 41.75 & 288 & 103.6 & 958 & 5.0 & -4.0 & 1428 & -1146 \\
\hline-70.75 & 42.25 & 63 & 210.7 & 40 & 16.2 & -32.9 & 1025 & -2081 \\
\hline-70.75 & 42.75 & 17 & 105.8 & 3 & 56.3 & -69.0 & 943 & -1155 \\
\hline \multicolumn{9}{|l|}{ MAR } \\
\hline-70.75 & 43.25 & 31 & 29.9 & 11 & 21.6 & -37.4 & 662 & -1146 \\
\hline-71.25 & 41.75 & 257 & 28.2 & 808 & 3.9 & -2.5 & 997 & -650 \\
\hline-71.75 & 41.25 & 21 & 112.4 & 4 & 35.2 & -32.6 & 726 & -672 \\
\hline-72.75 & 40.75 & 20 & 25.4 & 62 & 30.7 & -21.1 & 623 & -430 \\
\hline-72.75 & 41.25 & 10 & 142.5 & 2 & 150.8 & -36.9 & 1578 & -386 \\
\hline-72.75 & 41.75 & 55 & 476.6 & 3 & 55.9 & -45.7 & 3088 & -2523 \\
\hline-73.25 & 40.75 & 19 & 26.8 & 56 & 31.4 & -28.4 & 608 & -550 \\
\hline-74.25 & 40.75 & 1192 & 608.2 & 126 & 15.5 & -11.8 & 18432 & -14047 \\
\hline-75.25 & 38.25 & 399 & 80.5 & 172 & 13.9 & -5.0 & 5558 & -2016 \\
\hline-75.25 & 38.75 & 354 & 31.8 & 357 & 7.5 & -3.0 & 2659 & -1076 \\
\hline-75.25 & 39.75 & 1716 & 499.0 & 221 & 10.0 & -7.8 & 17072 & -13439 \\
\hline-75.75 & 39.25 & 224 & 18.3 & 434 & 7.5 & -2.9 & 1685 & -640 \\
\hline-76.25 & 39.25 & 3427 & 717.1 & 352 & 8.1 & -5.1 & 27646 & -17352 \\
\hline-76.75 & 37.25 & 586 & 272.3 & 74 & 15.0 & -10.4 & 8810 & -6084 \\
\hline-76.75 & 37.75 & 154 & 36.3 & 163 & 10.7 & -6.6 & 1654 & -1023 \\
\hline-76.75 & 39.25 & 59 & 71.2 & 29 & 48.6 & -34.6 & 2862 & -2038 \\
\hline-77.25 & 38.25 & 206 & 30.2 & 268 & 6.1 & -3.3 & 1265 & -676 \\
\hline-77.25 & 38.75 & 568 & 259.2 & 118 & 16.7 & -10.8 & 9488 & -6134 \\
\hline \multicolumn{9}{|l|}{ SAR } \\
\hline-78.25 & 34.25 & 48 & 167.4 & 7 & 122.5 & -62.4 & 5916 & -3015 \\
\hline-79.25 & 33.25 & 47 & 56.3 & 42 & 43.4 & -36.5 & 2056 & -1728 \\
\hline-79.25 & 33.75 & 45 & 291.4 & 8 & 85.1 & -78.7 & 3843 & -3551 \\
\hline-79.75 & 33.25 & 25 & 33.8 & 15 & 37.9 & -32.8 & 956 & -828 \\
\hline-80.25 & 32.75 & 25 & 31.0 & 50 & 48.8 & -42.5 & 1214 & -1057 \\
\hline-80.25 & 33.25 & 92 & 75.5 & 61 & 62.7 & -61.2 & 5769 & -5625 \\
\hline-80.75 & 32.25 & 71 & 21.1 & 182 & 12.9 & -7.0 & 918 & -501 \\
\hline-80.75 & 32.75 & 164 & 63.1 & 95 & 20.6 & -11.5 & 3372 & -1879 \\
\hline-81.25 & 31.75 & 92 & 71.7 & 45 & 25.7 & -20.9 & 2361 & -1926 \\
\hline-81.25 & 32.25 & 130 & 379.8 & 11 & 51.7 & -39.2 & 6732 & -5097 \\
\hline-81.75 & 30.75 & 34 & 18.7 & 61 & 17.5 & -14.7 & 602 & -505 \\
\hline-81.75 & 31.25 & 130 & 17.7 & 294 & 5.5 & -4.0 & 713 & -523 \\
\hline-81.75 & 31.75 & 56 & 350.5 & 4 & 72.7 & -67.4 & 4068 & -3770 \\
\hline
\end{tabular}

\subsection{Seasonal variability in estuarine carbon dynamics}

Carbon dynamics in estuaries of the US East Coast not only show a marked spatial variability but also vary on the sea- sonal timescale. Table 5 presents the seasonal distribution of NEM and $\mathrm{FCO}_{2}$ for each subregion. In the NAR, a strong seasonality is simulated for the NEM and the summer period contributes more than a third to the annually integrated 
value. The outgassing reveals a lower seasonal variability and is only slightly higher than summer outgassing during fall and lower during spring. In the MAR, summer contributes more to the NEM ( $>28 \%$ of the yearly total) than any other season, but seasonality is less pronounced than in the NAR. Here, $\mathrm{FCO}_{2}$ values are highest in winter and particularly low during summer. In the SAR, summer accounts for $30 \%$ of the NEM, while spring contributes $21 \% . \mathrm{FCO}_{2}$ is relatively constant throughout the year, suggesting that seasonal variations in carbon processing decrease towards the lower latitudes in the SAR. This is partly related to the low variability in river discharge throughout the year in lower latitudes (Table S1). In riverine-dominated systems with low residence times, such as, for instance, the Altamaha River estuary, the $\mathrm{CO}_{2}$ exchange at the air-water interface is mainly controlled by the river discharge because the time required to degrade the entire riverine organic matter flux exceeds the transit time of OC through the estuary. Therefore, the riverine-sustained outgassing is highest during the spring peak discharge periods. In contrast, the seasonal variability in $\mathrm{FCO}_{2}$ in longresidence, marine-dominated systems with large marsh areas (e.g., Sapelo and Doboy Sound) is essentially controlled by seasonal temperature variations. Its maximum is reached during summer when marsh plants are dying and decomposing, as opposed to spring when marshes are in their productive stage (Jiang et al., 2008). These contrasting seasonal trends have already been reported for different estuarine systems in Georgia, such as the Altamaha Sound, the Sapelo Sound, and the Doboy Sound (Cai, 2011). On the scale of the entire US East Coast, the seasonal trends in NEM reveal a clear maximum in summer and minimal values during autumn and winter. The seasonality of $\mathrm{FCO}_{2}$ is much less pronounced because the outgassing of oversaturated riverine waters throughout the year contributes to a large fraction of the $\mathrm{FCO}_{2}$ and dampens the effect of the temperature-dependent processes (NEM and denitrification). In our simulations, the competition between temperature and river discharge is the main driver of the seasonal estuarine carbon dynamics. When discharge increases, the carbon loads increase proportionally and the residence time within the system decreases, consequently limiting an efficient degradation of organic carbon input fluxes. In warm regions like the SAR, the temperature is sufficiently high all year round to sustain high $\mathrm{C}$ processing rates and this explains the reduced seasonal variability in NEM.

\subsection{Regional carbon budget: a comparative analysis}

The annual carbon budget for the entire US East Coast is summarized in Fig. 11a. The total carbon input to estuaries along the US East Coast is $4.6 \mathrm{Tg} \mathrm{C} \mathrm{yr}^{-1}$, of which $42 \%$ arrives in organic form and $58 \%$ in inorganic form. Of this total input, salt marshes contribute $0.6 \mathrm{Tg} \mathrm{C} \mathrm{yr}^{-1}$, which corresponds to about $14 \%$ of the total carbon loads and $32 \%$ of the organic loads in the region. The relative contribution of the salt marshes to the total carbon input increases towards low latitudes and is as high as $60 \%$ in the SAR re-

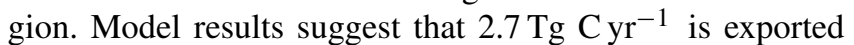
to the continental shelf ( $25 \%$ as TOC and $75 \%$ as DIC), while $1.9 \mathrm{Tg} \mathrm{Cyr}^{-1}$ is emitted to the atmosphere. The overall carbon-filtering capacity of the region thus equals $41 \%$ of the total carbon entering the 42 estuarine systems (river plus salt marshes). Because of the current lack of a benthic module in C-GEM, the water column carbon removal occurs entirely in the form of $\mathrm{CO}_{2}$ outgassing and does not account for the potential contribution of carbon burial in sediments. The estimated estuarine carbon retention presented here is thus likely a lower-bound estimate. Reported for the modeled surface area of the region, the total $\mathrm{FCO}_{2}$ value of 1.9 $\mathrm{Tg} \mathrm{C} \mathrm{yr}^{-1}$ translates into a mean air-water $\mathrm{CO}_{2}$ flux of about $14 \mathrm{~mol} \mathrm{C} \mathrm{m}^{-2} \mathrm{yr}^{-1}$. This value is slightly higher than the estimate of $10.8 \mathrm{~mol} \mathrm{C} \mathrm{m}^{-2} \mathrm{yr}^{-1}$ calculated by Laruelle et al. (2013) on the basis of local $\overline{\mathrm{FCO}}_{2}$ estimates assumed to be representative of yearly averaged conditions (see Sect. 2.1). The latter was calculated as the average of 13 annual $\overline{\mathrm{FCO}}_{2}$ values reported in the literature (Table 2), irrespective of the size of the systems. This approach is useful and widely used to derive regional and global carbon budgets (Borges et al., 2005; Laruelle et al., 2010; Chen et al., 2013). However, this approach may lead to potentially significant errors (Volta et al., 2016a) due to the uncertainty introduced by the spatial interpolation of local measurements to large regional surface areas, while useful and widely used for deriving regional and global carbon budgets.

Regional $\mathrm{C}$ budgets are sparse. To our knowledge, the only other published regional assessment of estuarine carbon and $\mathrm{CO}_{2}$ dynamics comes from a relatively well-studied region: the estuaries flowing into the North Sea in western Europe (Fig. 11b). This budget was calculated using a similar approach (Volta, 2016a) and thus provides an ideal opportunity for a comparative assessment of $\mathrm{C}$ cycling in these regions. However, it is important to note that there are also important differences in the applied model approaches and those differences should be taken into account when comparing the derived budgets. In particular, the northwestern European study is based on a simulation of only the six largest systems (Elbe, Scheldt, Thames, Ems, Humber, and Weser), accounting for about $40 \%$ for the riverine carbon loads of the region. It assumes that the intensity of carbon processing and evasion in all other smaller estuaries discharging into the North Sea (16\% of the carbon loads) can be represented by the average of the six largest system simulation results. In addition, the Rhine-Meuse system, which alone accounts for $44 \%$ of the carbon riverine inputs of the region, was treated as a passive conduit with respect to carbon due to its very short freshwater residence time (Abril et al., 2002). The contribution of salt marshes to the regional carbon budget was also ignored because their total surface area is much smaller than along the US East Coast (Regnier et al., 2013b). Another important difference is the inclusion of seasonality in the present study, 
Table 5. Seasonal contribution to $\mathrm{FCO}_{2}$ and NEM in each subregion. The seasons displaying the highest percentages are indicated in bold. Winter is defined as January, February, and March; spring is defined as April, May, and June, and so on.

\begin{tabular}{lrrrrrrrrrrr}
\hline Region & $\begin{array}{r}S \\
\mathrm{~km}^{2}\end{array}$ & $\begin{array}{r}\text { NEM } \\
\mathrm{mol} \mathrm{C} \mathrm{yr}\end{array}$ & $\begin{array}{r}\text { Winter } \\
\%\end{array}$ & $\begin{array}{r}\text { Spring } \\
\%\end{array}$ & $\begin{array}{r}\text { Summer } \\
\%\end{array}$ & $\begin{array}{r}\text { Fall } \\
\%\end{array}$ & $\begin{array}{r}\mathrm{FCO}_{2} \\
\mathrm{~mol} \mathrm{C} \mathrm{yr}^{-1}\end{array}$ & $\begin{array}{r}\text { Winter } \\
\%\end{array}$ & $\begin{array}{r}\text { Spring } \\
\%\end{array}$ & $\begin{array}{r}\text { Summer } \\
\%\end{array}$ & $\begin{array}{r}\text { Fall } \\
\%\end{array}$ \\
\hline NAR & 558 & $-16.310^{9}$ & 14.7 & 21.2 & $\mathbf{3 7 . 0}$ & 27.2 & $7.210^{9}$ & 26.3 & 18.9 & 26.5 & $\mathbf{2 8 . 3}$ \\
MAR & 9298 & $-72.210^{9}$ & 21.9 & 25.9 & $\mathbf{2 8 . 8}$ & 23.4 & $108.310^{9}$ & $\mathbf{2 9 . 8}$ & 23.3 & 20.7 & 26.2 \\
SAR & 959 & $-30.510^{9}$ & 24.6 & 20.9 & $\mathbf{3 0 . 3}$ & 24.2 & $39.210^{9}$ & 26 & 23.4 & $\mathbf{2 7}$ & 23.6 \\
\hline
\end{tabular}

while the budget calculated for the North Sea is derived from yearly average conditions (Volta et al., 2016a).

Overall, although both regions receive similar amounts of

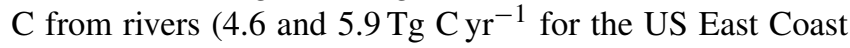
and the North Sea, respectively), they reveal significantly different carbon-filtering capacities. While the estuaries of the US East Coast filter $41 \%$ of the riverine TC loads, those from the North Sea only remove $8 \%$ of the terrestrially derived material. This is partly due to the large amounts of carbon transiting through the passive Rhine-Meuse system. The regional filtering capacity is higher $(15 \%)$ when this system is excluded from the analysis. However, even when neglecting this system, significant differences in filtering efficiencies between both regions remain. The $\mathrm{FCO}_{2}$ value from the North Sea estuaries $\left(0.5 \mathrm{Tg} \mathrm{Cyr}^{-1}\right)$ is significantly lower than the 1.9 $\mathrm{Tg} \mathrm{C} \mathrm{yr}^{-1}$ computed for the US East Coast. The reason for the lower evasion rate in northwestern European estuaries is essentially twofold. First, the total cumulative surface area available for gas exchange is significantly lower along the North Sea, in spite of comparable flux densities calculated using the entire estuarine surface areas of both regions (14 and $23 \mathrm{~mol} \mathrm{C} \mathrm{m}^{-2} \mathrm{yr}^{-1}$ for the US East Coast and the North Sea, respectively). Second, although the overall riverine carbon loads are comparable in both regions (Fig. 11), the ratio of organic to inorganic matter input is much lower in the North Sea area because the regional lithology is dominated by carbonate rocks and mixed sediments that contain carbonates (Dürr et al., 2005; Hartmann et al., 2012). As a consequence, TOC represents less than $20 \%$ of the riverine loads and only $10 \%$ of the carbon exported to the North Sea. In both regions, however, the increase in the ratio of inorganic to organic carbon between input and output is sustained by a negative NEM (Fig. 11). Although the ratios themselves may significantly vary from one region of the world to another, as evidenced by these two studies, a NEM-driven increase in the inorganic fraction within carbon load along the estuarine axis is consistent with the global estuarine carbon budget proposed by Bauer et al. (2013). On the US East Coast, the respiration of riverine $\mathrm{OC}$ within the estuarine filter is partly compensated for by $\mathrm{OC}$ inputs from marshes and mangroves in such a way that the input and export IC/OC ratios are closer than in the North Sea region.

\subsection{Scope of applicability and model limitations}

Complex multidimensional models are now increasingly applied to quantitatively explore carbon and nutrient dynamics along the land-ocean transition zone on seasonal and even annual timescales (Garnier et al., 2001; Arndt et al., 2007, 2009; Arndt and Regnier, 2007; Mateus et al., 2012). However, the application of such complex models remains limited to individual, well-constrained systems due their high data requirements and computational demand resulting from the need to resolve important physical, biogeochemical, and geological processes on relevant temporal and spatial scales. The one-dimensional, computationally efficient model C-GEM has been specifically designed to reduce data requirements and computational demand and to enable regional and/or global scale applications (Volta et al., 2014, 2016a). However, such a low data demand and computational efficiency inevitably requires simplification. The following paragraphs critically discuss these simplifications and their implications.

\subsubsection{Spatial resolution}

Here, C-GEM is used with a $0.5^{\circ}$ spatial resolution. While this resolution captures the features of large systems, it is still very coarse for relatively small watersheds, such as those of the St. Francis River, Piscataqua River, May River, or Sapelo River. For instance, the five estuaries reported by Hunt et al. (2010, 2011, see sect. 2.6) are all small systems covered by the same watershed at a $0.5^{\circ}$ resolution. Only watersheds whose areas span several grid cells can be properly identified and represented (i.e., Merrimack or Penobscot with six and nine cells, respectively).

\subsubsection{Hydrodynamic and transport model}

C-GEM is based on a theoretical framework that uses idealized geometries and significantly reduces data requirements. These idealized geometries are fully described by three easily obtainable geometrical parameters $(B, B 0$, and $H)$. The model thus approximates the variability in estuarine width and cross section along the longitudinal axis through a set of exponential functions. A comprehensive sensitivity study (Volta et al., 2014) has shown that integrated process rates are generally sensitive to changes in these geometrical parameters because of their control on estuarine residence times. 
(a) Eastern US coast

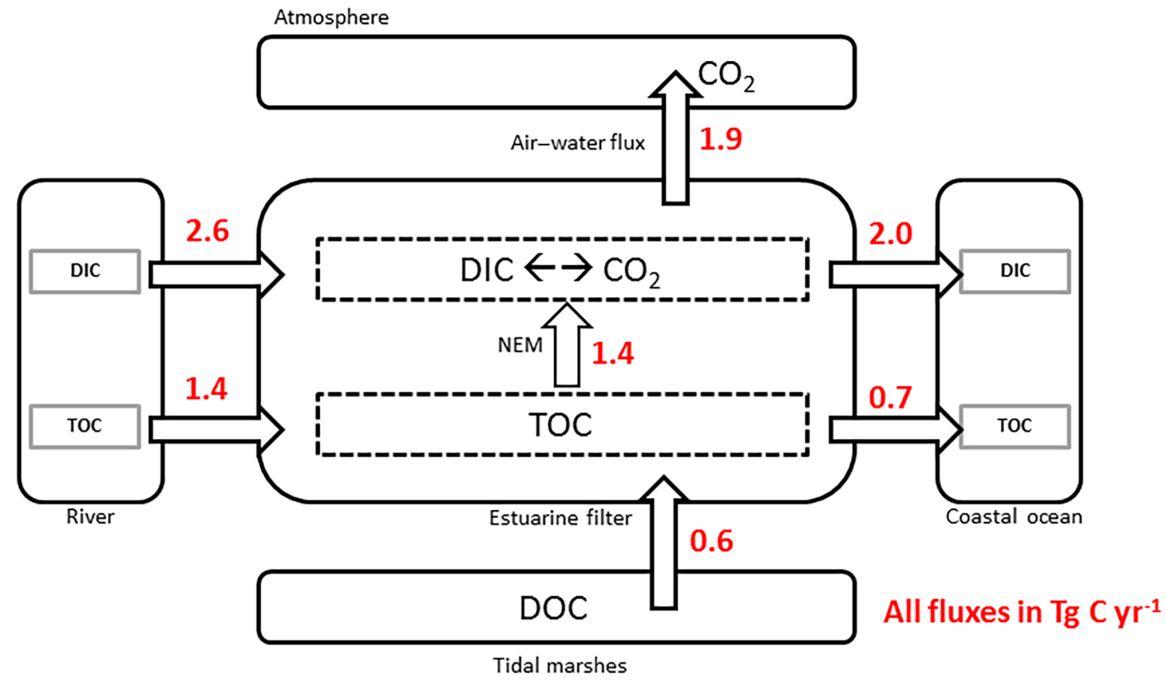

(b) North Sea coast

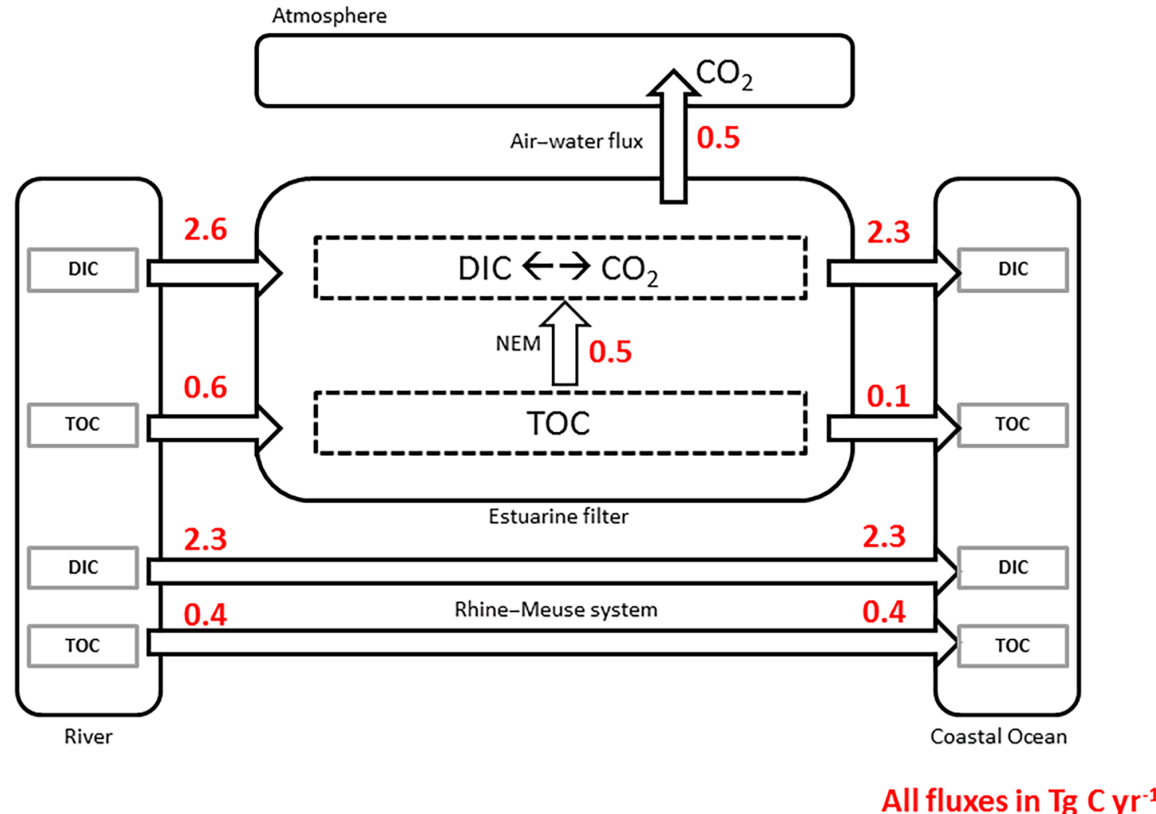

Figure 11. Annual carbon budget of the estuaries of the US East Coast (a) and of the coast of the North Sea (b; modified from Volta et al., 2016a).

For instance, Volta et al. (2014) demonstrated that the NEM is particularly sensitive to the convergence length. Similarly, the use of constant depth profile may lead to variations of about $10 \%$ in NEM (Volta et al., 2014). Nevertheless, geometrical parameters are generally easy to constrain, especially in well-monitored regions such as the US East Coast. Here, all geometrical parameters are constrained on the basis of observed estuarine surface areas and average water depths. In addition, the model also accounts for the slope of the estuarine channel. This approach ensures that simulated estuarine surface areas, volumes, and thus residence times are in good agreement with those of the real systems and it minimizes uncertainties associated with the physical setup.

In addition, the one-dimensional representation of the idealized estuarine systems does not resolve two- or threedimensional circulation features induced by complex topography and density-driven circulation. While C-GEM performs well in representing the dominant longitudinal gradients, its applicability to branched systems or those with aspect ratios for which a dominant axis is difficult to identify 
(e.g., Blackwater estuary, UK; Pearl River estuary, China; Tagus estuary, Portugal; Bay of Brest, France) is limited.

\subsubsection{Biogeochemical model}

Although the reaction network of C-GEM accounts for all processes that control estuarine $\mathrm{FCO}_{2}$ (Borges and Abril, 2012; Cai, 2011), several, potentially important processes, such as benthic-pelagic exchange processes, phosphorous sorption-desorption and mineral precipitation, a more complex representation of the local phytoplankton community, grazing by higher trophic levels, or multiple reactive organic carbon pools, are not included. Although these processes are difficult to constrain and their importance for $\mathrm{FCO}_{2}$ is uncertain, the lack of their explicit representations induces uncertainties in CFilt. In particular, the exclusion of benthic processes such as organic matter degradation and burial in estuarine sediments could result in an underestimation of CFilt. However, because very little is known on the long-term fate of organic carbon in estuarine sediments, setting up and calibrating a benthic module proves a difficult task. Furthermore, to a certain degree, model parameters (such as organic matter degradation and denitrification rate constant) implicitly account for benthic dynamics. We nonetheless acknowledge that, by ignoring benthic processes and burial in particular, our estimates for the estuarine carbon filtering may be underestimated, particularly in the shallow systems of the SAR.

Biogeochemical model parameters for regional and global applications are notoriously difficult to constrain (Volta et al., 2016b). Model parameters implicitly account for processes that are not explicitly resolved and their transferability between systems is thus limited. In addition, published parameter values are generally biased towards temperate regions in industrialized countries (Volta et al., 2016b). A first-order estimation of the parameter uncertainty associated with the estuarine carbon removal efficiency (CFilt) can be extrapolated from the extensive parameter sensitivity analyses carried out by Volta et al. (2014, 2016b). These comprehensive sensitivity studies on end-member systems have shown that the relative variation in CFilt when a number of key biogeochemical parameters are varied by 2 orders of magnitude varies by $\pm 15 \%$ in prismatic (short residence time on the order of days) to $\pm 25 \%$ in funnel-shaped (long residence time) systems. Thus, assuming that uncertainty increases linearly between those bounds as a function of residence time, an uncertainty estimate can be obtained for each of our modeled estuaries. With this simple method, the simulated regional CFilt value of $1.9 \mathrm{Tg} \mathrm{Cyr}^{-1}$ would be associated with an uncertainty range comprised between 1.5 and $2.2 \mathrm{Tg} \mathrm{C} \mathrm{yr}^{-1}$. Our regional estuarine $\mathrm{CO}_{2}$ evasion estimate is thus reported with moderate confidence. Furthermore, in the future, this uncertainty range could be further constrained using statistical methods such as Monte Carlo simulations (e.g., Lauerwald et al., 2015).

\subsubsection{Boundary conditions and forcings}

In addition, simulations are only performed for climatological means over the period 1990-2010 without resolving interannual and secular variability. Boundary conditions and forcings are critical as they place the modeled system in its environmental context and drive transient dynamics. However, for regional applications, temporally resolved boundary conditions and forcings are difficult to constrain. C-GEM places the lower boundary condition $20 \mathrm{~km}$ from the estuarine mouth into the coastal ocean and the influence of this boundary condition on simulated biogeochemical dynamics is thus limited. At the lower boundary condition, direct observations for nutrients and oxygen are extracted from databases such as the World Ocean Atlas (Antonov et al., 2010). However, lower boundary conditions for $\mathrm{OC}$ and $p \mathrm{CO}_{2}$ (zero concentration for $\mathrm{OC}$ and assumption of $p \mathrm{CO}_{2}$ equilibrium at the seaside) are simplified. This approach does not allow the address of the additional complexity introduced by biogeochemical dynamics in the estuarine plume (see Arndt et al., 2011). However, these dynamics only play a secondary role in the present study, which focuses on the role of the estuarine transition zone in processing terrestrially derived carbon.

Constraining upper boundary conditions and forcings is thus more critical. Here, C-GEM is forced by seasonally averaged conditions for $Q, T$, and radiation. To date, Global NEWS only provides yearly averaged conditions for a number of upper boundary conditions (Seitzinger et al., 2005; Mayorga et al., 2010), representative of the year 2000. Simulations are thus only partly transient (induced by seasonality in $Q, T$, and radiation) and do not resolve short-lived events such as storms or extreme drought conditions. In addition, direct observations of upper boundary conditions are rarely available, in particular over seasonal or annual timescales. For the US East Coast estuaries, direct observations are only available for $\mathrm{O}_{2}$, chlorophyll $a$, DIC, and ALK. For DIC and alkalinity, boundary conditions are constrained by calculating the average concentration over a period of about 3 decades. In addition, observational data are extracted at the station closest to the model's upper boundary, which might still be located several kilometers upstream or downstream of the model boundary. Upper boundary conditions of POC, DOC, DIN, DIP, and DSi are extracted from Global NEWS and are thus model-derived. As a consequence, our results are thus intimately dependent on the robustness of the Global NEWS predictions. These values are usually only considered as robust estimates for watersheds larger than $\sim 10$ cells (Beusen et al., 2005), which only correspond to 13 of the 42 estuaries modeled in this study.

\subsubsection{Model-data comparison}

The generic nature of the applied model approach renders a direct validation of model results on the basis of local and instantaneous observational data (e.g., longitudinal profiles) 
difficult. In particular the applications of seasonally and/or annually averaged or model-deduced boundary conditions, which are not likely representative of these long-term average conditions, do not lend themselves well to comparison with punctual measurements. Therefore, model performance is evaluated on the basis of spatially aggregated estimates (e.g., regional $\mathrm{FCO}_{2}$ estimates based on local measurements) rather than system-to-system comparisons with longitudinal profiles from specific days. However, note that the performance of C-GEM has been intensively tested by specific model-data comparisons for a number of different systems (e.g., Volta et al., 2014, 2016a) and we are thus confident of its predictive capabilities.

Despite the numerous simplifying assumptions inevitably required for such a regional assessment of carbon fluxes along the land-ocean continuum, the presented approach does nevertheless provide an important step forward in evaluating the role of land-ocean transition systems in the global carbon cycle. It provides a first robust estimate of carbon dynamics based on a theoretically well-founded and carefully tested, spatially and temporally resolved model approach. This approach provides novel insights that go beyond those gained through traditionally applied zero-salinity methods or box model approaches. In addition, it also highlights critical variables and data gaps and thus helps guide efficient monitoring strategies.

\subsection{Towards predictors of the estuarine carbon processing}

The mutual dependence of geometry and transport on each other in tidal estuaries and, ultimately, their biogeochemical functioning (Savenije, 1992; Volta et al., 2014), allows the relation of easily extractable parameters linked to their shape or hydraulic properties to biogeochemical indicators. In this section, we explore the relationships between such simple physical parameters and indicators of the estuarine carbon processing $\overline{\mathrm{NEM}}, \overline{\mathrm{FCO}}_{2}$, and CFilt. In order to account for the effect of temperature on $\mathrm{C}$ dynamics, $-\overline{\mathrm{NEM}}$ and $\overline{\mathrm{FCO}}_{2}$ are also normalized to the same temperature (arbitrarily chosen to be $0^{\circ} \mathrm{C}$ ). These normalized values are obtained by dividing $-\overline{\mathrm{NEM}}$ and $\overline{\mathrm{FCO}}_{2}$ by a $Q_{10}$ function $f(T)$ (see Volta et al., 2014). This procedure allows the consideration of the exponential increase in the rate of several temperature-dependent processes contributing to the NEM (photosynthesis, organic carbon degradation, etc.). Applying the same normalization to $-\overline{\mathrm{NEM}}$ and $\overline{\mathrm{FCO}}_{2}$ is a way of testing how intimately linked NEM and $\mathrm{FCO}_{2}$ are in estuarine systems. Indeed, linear relationships relating one to the other have been reported (Mayer and Eyre, 2012). The three indicators are then investigated as a function of the ratio between the estuarine surface $S$ and the seasonal river discharge $Q$. The surface area is calculated from the estuarine width and length, as described by Eq. (2), in order to use a parameter that is potentially applicable to other regions for which direct estimates of the real estuarine surface area are not available. Since the freshwater residence time of a system is obtained by dividing volume by river discharge, the $S / Q$ ratio is also intimately linked to residence time. Here, we choose to exclude the estuarine depth from the analysis because this variable cannot be easily quantified from maps or remote sensing images and would thus compromise the applicability of a predictive relationship on the global scale. However, from dimensional analysis, $S / Q$ can be viewed as a water residence time normalized to meter depth of water. As shown by Eq. (3), $S$ only requires constraining $B 0$ and width convergence length $b$, two parameters that can readily be extracted from the Google Earth engine. Global databases of river discharges, as for instance RivDIS (Vörösmarty et al., 1996), are also available in such a way that the $S / Q$ ratio can potentially be extracted for all estuaries around the globe.

Figure 12a reveals that small values of $S / Q$ are associated with the most negative $\overline{\mathrm{NEM}} / f(T)$. The magnitude of the $\overline{\text { NEM }}$ then exponentially decreases with increasing values of $S / Q$. Estuaries characterized by small values of $S / Q$ are mainly located in the NAR subregion and correspond to small surface area, and thus short-residence-time systems. It is possible to quantitatively relate $-\overline{\mathrm{NEM}} / f(T)$ and $S / Q$ through a power-law function $\left(y=25.85 x^{-0.64}\right.$ with $r^{2}=0.82$ ). The coefficient of determination remains the same when excluding estuaries from the NAR region and the equation itself is not significantly different, although those estuaries on their own do not display any statistically significant trend (Table 6). The decrease in the intensity of the net ecosystem metabolism in larger estuaries (Fig. 8), characterized by high $S / Q$ ratios, can be related to the extensive consumption of the organic matter pool during its transit through the estuarine filter. However, when reported for the entire surface area of the estuary, larger systems (with high values of $S / Q$ ) still reveal the most negative surface-integrated NEM (Fig. 12b). It can also be noted that some estuaries from the NAR region display very low values of - NEM. These data points correspond to fall and winter simulations for which the temperature was relatively cold $\left(<5^{\circ} \mathrm{C}\right)$ and biogeochemical processing was very low.

The overall response of $\overline{\mathrm{FCO}}_{2} / f(T)$ to $S / Q$ is comparable to that of $-\overline{\mathrm{NEM}} / f(T)$ (Fig. 12c), with lower values of $\overline{\mathrm{FCO}}_{2}$ observed for high values of $S / Q$. However, for $S / Q<3$ days $\mathrm{m}^{-1}$, the $\overline{\mathrm{FCO}}_{2}$ values are very heterogeneous and contain many, low- $\overline{\mathrm{FCO}}_{2}$ outliers from the NAR region. These data points generally correspond to low-water-temperature conditions, which keep $p \mathrm{CO}_{2}$ low, even if the system internally generates enough $\mathrm{CO}_{2}$ via NEM. Thus, the well-documented correlation between $\overline{\mathrm{NEM}}$ and $\overline{\mathrm{FCO}}_{2}$ (Maher and Eyre, 2012) does not seem to hold for systems with very short residence times. For systems with $S / Q>3$ days $\mathrm{m}^{-1}$, we obtain a regression $\mathrm{FCO}_{2}=-0.64 \times \mathrm{NEM}+5.96$ with $r^{2}=0.46$, which compares well with the relation $\mathrm{FCO}_{2}=-0.42 \times \mathrm{NEM}+12$ proposed by Maher and Eyre (2012), who used 24 sea- 


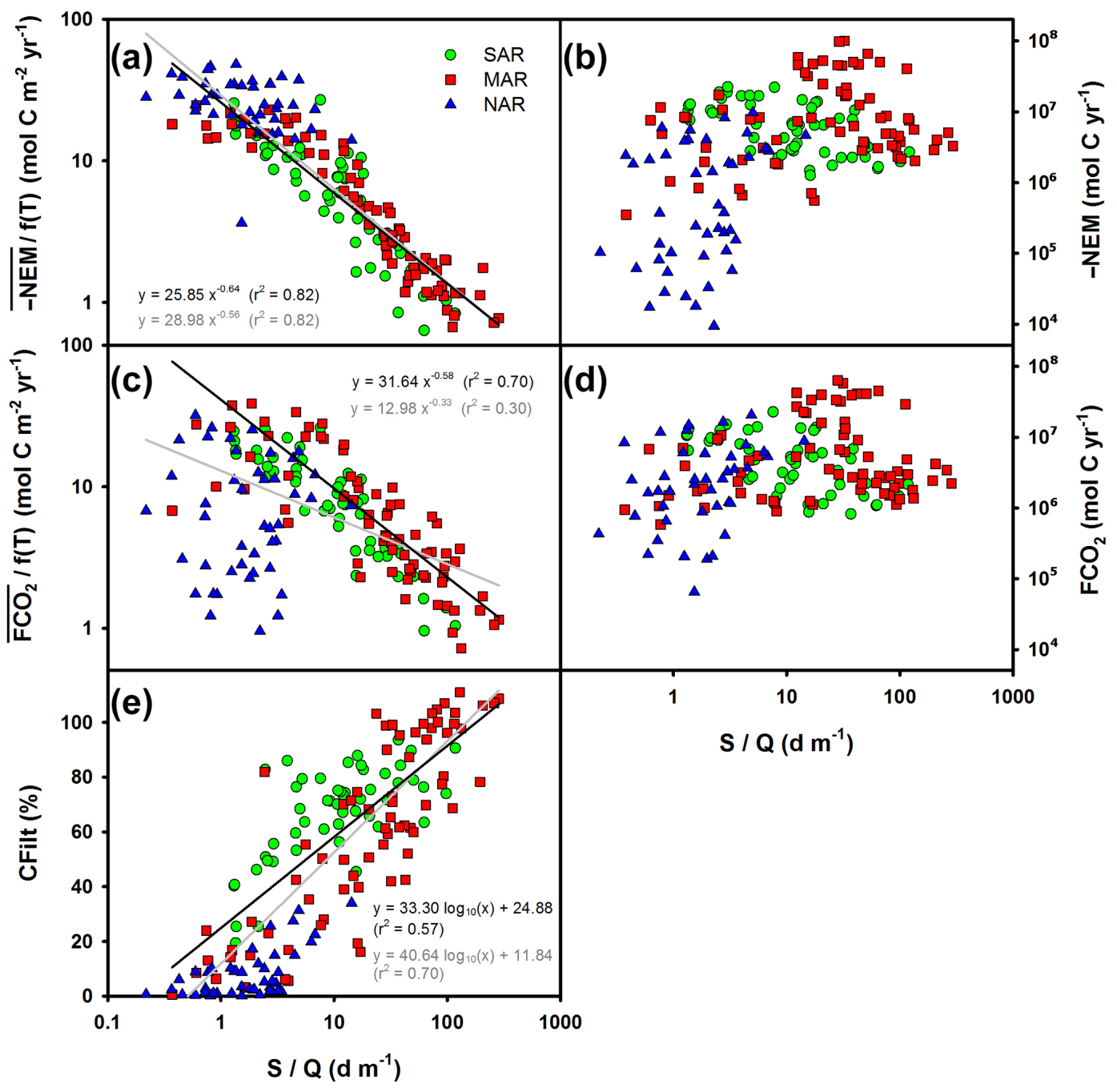

Figure 12. System-scale integrated biogeochemical indicators expressed as functions of the depth-normalized residence time expressed as the ratio of the estuarine surface $S$ and the river discharge $Q$ for all seasons. Panels (b), (d), and (e) represent $-\mathrm{NEM}_{\text {, FCO }}$, and $\mathrm{CFilt}_{\text {, }}$ respectively. Panels (a) and (c) represent $-\mathrm{NEM}$ and $\mathrm{FCO}_{2}$ normalized by a temperature $Q_{10}$ function. Black lines are the best-fitted linear regressions obtained using all the points. Grey lines are best fit using only the estuaries from the MAR and SAR regions.

sonal estimates from small Australian estuaries. However, our results suggest that this relationship cannot be extrapolated to small systems such as those located in the NAR. Figure 12d, which reports non-normalized $\mathrm{FCO}_{2}$, reveals a monotonous increase in $\mathrm{FCO}_{2}$ with $S / Q$. This suggests that, unlike the NEM for which the normalization by a temperature function allow the explanation of most of the variability, $\mathrm{FCO}_{2}$ is mostly controlled by the water residence time within the system. Discharge is the main $\mathrm{FCO}_{2}$ driver in riverinedominated systems, while interactions with marshes drive the outgassing in marine-dominated systems surrounded by marshes. Net aquatic biological production (NEM being negative or near 0) in large estuaries (with large $S / Q$ ) is another important reason for low $\mathrm{FCO}_{2}$ in such systems. For example, despite the higher $\mathrm{CO}_{2}$ degassing flux in the upper estuary of the Delaware, strong biological $\mathrm{CO}_{2}$ uptake in the mid-bay and near zero NEM in the lower bay result in a much lower $\mathrm{FCO}_{2}$ for the entire estuary (Joesoef et al., 2015). In systems with $S / Q<3$ days $\mathrm{m}^{-1}$, the short-residence-time prevents the excess $\mathrm{CO}_{2}$ of oversaturated water from being entirely exchanged with the atmosphere and simulations reveal that the estuarine waters are still oversaturated in $\mathrm{CO}_{2}$ at the estuarine mouth. Thus, the inorganic carbon, produced by the decomposition of organic matter, is not outgassed within the estuary but exported to the adjacent continental shelf waters. This result is consistent with the observation-based hypothesis of Laruelle et al. (2015) for the NAR estuaries. As a consequence of the distinct behavior of short residence time systems, the coefficient of determination of the best-fitted power-law function relating $\overline{\mathrm{FCO}}_{2}$ and $S / Q$ is only significant if NAR systems are excluded $\left(y=31.64 x^{-0.58}\right.$ with $r^{2}=0.70$ ). This thus suggests that such relationships (as well 
Table 6. Regressions and associated coefficient of determination between the depth-normalized residence time $(S / Q)$ and $-\overline{\mathrm{NEM}} / f(T)$, $\overline{\mathrm{FCO}}_{2} / f(T)$, and CFilt.

\begin{tabular}{|c|c|c|c|}
\hline Region & $-\overline{\mathrm{NEM}} / f(T)$ & $\overline{\mathrm{FCO}}_{2} / f(T)$ & CFilt \\
\hline NAR & $\begin{array}{l}y=27.84 x^{-0.17} \\
r^{2}=0.11\end{array}$ & $\begin{array}{l}y=6.07 x^{0.00} \\
r^{2}=0.00\end{array}$ & $\begin{array}{l}y=15.08 \\
\log _{10}(x)+4.86 \\
r^{2}=0.40\end{array}$ \\
\hline MAR & $\begin{array}{l}y=26.03 x^{-0.63} \\
r^{2}=0.86\end{array}$ & $\begin{array}{l}y=34.36 x^{-0.58} \\
r^{2}=0.68\end{array}$ & $\begin{array}{l}y=40.46 \\
\log _{10}(x)+9.60 \\
r^{2}=0.70\end{array}$ \\
\hline SAR & $\begin{array}{l}y=28.36 x^{-0.71} \\
r^{2}=0.76\end{array}$ & $\begin{array}{l}y=32.82 x^{-0.66} \\
r^{2}=0.80\end{array}$ & $\begin{array}{l}y=23.19 \\
\log _{10}(x)+43.71 \\
r^{2}=0.46\end{array}$ \\
\hline MAR + SAR & $\begin{array}{l}y=25.85 x^{-0.64} \\
r^{2}=0.82\end{array}$ & $\begin{array}{l}y=31.64 x^{-0.58} \\
r^{2}=0.70\end{array}$ & $\begin{array}{l}y=33.30 \\
\log _{10}(x)+24.88 \\
r^{2}=0.57\end{array}$ \\
\hline $\mathrm{NAR}+\mathrm{MAR}+\mathrm{SAR}$ & $\begin{array}{l}y=28.98 x^{-0.66} \\
r^{2}=0.82\end{array}$ & $\begin{array}{l}y=12.98 x^{-0.33} \\
r^{2}=0.30\end{array}$ & $\begin{array}{l}y=40.64 \\
\log _{10}(x)+11.84 \\
r^{2}=0.70\end{array}$ \\
\hline
\end{tabular}

as that proposed by Maher and Eyre, 2012) cannot be applied

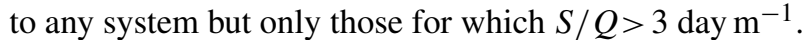

Finally, Fig. 12e reports the simulated mean seasonal carbon-filtering capacities as functions of the depthnormalized residence time. Not surprisingly, and in overall agreement with previous studies on nutrient dynamics in estuaries (Nixon et al., 1996), the carbon-filtering capacity increases with $S / Q$. The best statistical relation between CFilt and $S / Q$ is obtained when including all three regions, resulting in $r^{2}=0.70\left(y=40.64 \log _{10}(x)+11.84\right)$. Very little $\mathrm{C}$ removal occurs in systems with $S / Q<1$ day $\mathrm{m}^{-1}$. For systems characterized by longer depth-normalized residence times, CFilt increases regularly and reaches $100 \%$ for $S / Q>100$ day $\mathrm{m}^{-1}$. Such high values are only observed for very large estuaries from the MAR region (Delaware and Chesapeake bays); the majority of our systems had an $S / Q$ range between 1 and 100 day $\mathrm{m}^{-1}$. The quantitative assessment of estuarine filtering capacities is further complicated by the complex interplay of estuarine and coastal processes. Episodically, marked spatial variability in concentration gradients near the estuarine mouth may lead to a reversal of net material fluxes from coastal waters into the estuary (Regnier at al., 1998; Arndt et al., 2011). Our results show that this feature is particularly significant for estuaries with a large width at the mouth and short convergence length (funnel-shaped or bay-type systems). These coastal nutrient and carbon inputs influence the internal estuarine $\mathrm{C}$ dynamics and lead to filtering capacities that can exceed $100 \%$. This feature is particularly significant in summer, when riverine inputs are low and the marine material is intensively processed inside the estuary.

Previous work investigated the relationship between freshwater residence time and nutrient retention (Nixon et al., 1996; Arndt et al., 2011; Laruelle, 2009). These studies, how- ever, were constrained by the scarcity of data. For instance, the pioneering work of Nixon et al. (1996) only relied on a very limited number $(<10)$ of quite heterogeneous coastal systems, all located along the North Atlantic. Here, our modeling approach allows us to generate $168(42 \times 4)$ data points, each representing a system-scale biogeochemical behavior. Together, this database spans the entire spectrum of estuarine settings and climatic conditions found along the US East Coast. In addition, the ratio $S / Q$ used as a master variable for predicting temperature-normalized $-\overline{\mathrm{NEM}}, \overline{\mathrm{FCO}}_{2}$, and CFilt only requires a few easily accessible geometric parameters $(B 0, b$, and $L)$ and an estimate of the river discharge. While it is difficult to accurately predict $\overline{\mathrm{FCO}}_{2}$ for small systems such as those located in the NAR region, the relationships found are quite robust for systems in which $S / Q>3$ days $\mathrm{m}^{-1}$. Most interestingly, CFilt values reveal a significant correlation with $S / Q$ and could be used in combination with global riverine carbon delivery estimates such as Global NEWS 2 (Mayorga et al., 2010) to constrain the estuarine $\mathrm{CO}_{2}$ evasion and the carbon export to the coastal ocean on the continental and global scales.

\section{Conclusions}

This study presents the first complete estuarine carbon budget for the US East Coast using a modeling approach. The structure of the model C-GEM relies on a restricted number of readily available global data sets to constrain boundary conditions and limits the number of geometrical and physical parameters to be constrained. Our simulations predict a total $\mathrm{CO}_{2}$ outgassing of $1.9 \mathrm{Tg} \mathrm{C} \mathrm{yr}^{-1}$ for all tidal estuaries of the US East Coast. This quantification accounts for the seasonality in estuarine carbon processing as well as for distinct 
individual behaviors among estuarine types (marine or river dominated). The total carbon output to the coastal ocean is estimated at $2.7 \mathrm{Tg} \mathrm{C} \mathrm{yr}^{-1}$, and the carbon-filtering capacity with respect to riverine, marsh, and mangrove inputs is thus on the order of $40 \%$. This value is significantly higher than the recently estimated carbon-filtering capacity for estuaries surrounding the North Sea using a similar approach (Volta et al., 2016a), mainly because the surface area available for gas exchange and the draining lithology limits the $\mathrm{CO}_{2}$ evasion in the northwestern European systems. On the regional scale of the US East Coast estuaries, net heterotrophy is the main driver $(50 \%)$ of the $\mathrm{CO}_{2}$ outgassing, followed by the ventilation of riverine supersaturated waters entering the estuarine systems (32\%) and nitrification (18\%). The dominant mechanisms for the gas exchange and the resulting carbonfiltering capacities nevertheless reveal a clear latitudinal pattern, which reflects the shapes of estuarine systems, climatic conditions, and dominant land-use characteristics.

Our model results are used to derive predictive relationships relating the intensity of the area-based net ecosystem metabolism ( $\overline{\mathrm{NEM}})$, air-water $\mathrm{CO}_{2}$ exchange $\left(\overline{\mathrm{FCO}}_{2}\right)$, and the carbon-filtering capacity (CFilt) to the depth-normalized residence time, expressed as the ratio of the estuarine surface area to the river discharge. In the future, such simple relationships relying on readily available geometric and hydraulic parameters could be used to quantify carbon processing in areas of the world devoid of direct measurements. However, it is important to note that such simple relationships are only valid over the range of boundary conditions and forcings explored and may not be applicable to conditions that fall outside of this range. In regions with better data coverage, such as the one investigated here, our study highlights that the regional-scale quantification, attribution, and projection of estuarine biogeochemical cycling are now within reach.

Data availability. All the boundary conditions necessary to perform the simulations presented in this study are provided in the Supplement. Their calculations and the data sources used are detailed in Sect. 2.4. The original code of the generic version of the C-GEM model is available at doi:10.5194/gmd-7-1271-2014 (Volta et al., 2014).

\section{The Supplement related to this article is available online at doi:10.5194/bg-14-2441-2017-supplement.}

Competing interests. The authors declare that they have no conflict of interest.

Acknowledgements. Goulven Gildas Laruelle is Chargé de recherches du F.R.S.-FNRS at the Université Libre de Bruxelles. The research leading to these results has received funding from the European Union's Horizon 2020 research and innovation pro- gramme under the Marie Skłodowska-Curie grant agreement no. 643052 (C-CASCADES project). The authors thank V. L. Mulder for her thorough reading of the manuscript upon submission.

Edited by: M. Grégoire

Reviewed by: two anonymous referees

\section{References}

Abril, G., Nogueira, M., Etcheber, H., Cabeçadas, G., Lemaire, E., and Brogueira, M. J.: Behaviour of organic carbon in nine contrasting European estuaries, Estuar. Coast. Shelf Sci., 54, 241262, 2002.

Antonov, J. I., Seidov, D., Boyer, T. P., Locarnini, R. A., Mishonov, A. V., Garcia, H. E., Baranova, O. K., Zweng, M. M., and Johnson, D. R.: World Ocean Atlas 2009, 2, 184 pp., 2010.

Arndt, S., Vanderborght, J. P., and Regnier, P.: Diatom growth response to physical forcing in a macrotidal estuary: Coupling hydrodynamics, sediment transport, and biogeochemistry, J. Geophys. Res.-Ocean., 112, C05045, doi:10.1029/2006JC003581, 2007.

Arndt, S. and Regnier, P.: A model for the benthic-pelagic coupling of silica in estuarine ecosystems: sensitivity analysis and system scale simulation, Biogeosciences, 4, 331-352, doi:10.5194/bg-4331-2007, 2007.

Arndt, S., Regnier, P., and Vanderborght, J. P.: Seasonally-resolved nutrient export fluxes and filtering capacities in a macrotidal estuary, J. Mar. Syst., 78, 42-58, 2009.

Arndt, S., Lacroix, G., Gypens, N., Regnier, P., and Lancelot, C.: Nutrient dynamics and phytoplankton development along an estuary-coastal zone continuum: A model study, J. Mar. Syst., 84, 49-66, 2011.

Atlas, R., Hoffman, R. N., Ardizzone, J., Leidner, S. M., Jusem, J. C., Smith, D. K., and Gombos, D.: A cross-calibrated, multiplatform ocean surface wind velocity product for meteorological and oceanographic applications, Bull. Am. Meteorol. Soc., 92, 157-174, 2011.

Baklouti, M., Chevalier, C., Bouvy, M., Corbin, D., Pagano, M., Troussellier, M., and Arfi, R.: A study of plankton dynamics under osmotic stress in the Senegal River Estuary, West Africa, using a 3D mechanistic model, Ecol. Model., 222, 2704-2721, 2011.

Bauer, J. E., Cai, W. J., Raymond, P. A., Bianchi, T. S., Hopkinson, C. S., and Regnier, P. A. G.: The changing carbon cycle of the coastal ocean, Nature, 504, 61-70, doi:10.1038/nature12857, 2013.

Beusen, A. H. W., Dekkers, A. L. M., Bouwman, A. F., Ludwig,W., and Harrison, J.: Estimation of global river transport of sediments and associated particulate C, N, and P, Global Biogeochem. Cy., 19, GB4S05, doi:10.1029/2005GB002453, 2005.

Beusen, A. H. W., Bouwman, A. F., Dürr, H. H., Dekkers, A. L. M., and Hartmann, J.: Global patterns of dissolved silica export to the coastal zone: Results from a spatially explicit global model, Global Biogeochem. Cy., 23, GB0A02, doi:10.1029/2008GB003281, 2009.

Borges, A. V. and Abril, G.: Carbon Dioxide and Methane Dynamics in Estuaries, in: Treatise on Estuarine and Coastal Science, 
edited by: Wolanski, E. and McLusky, D. S., Academic Press, Waltham, 119-161, 2012.

Borges, A. V., Delille, B., and Frankignoulle, M.: Budgeting sinks and sources of $\mathrm{CO}_{2}$ in the coastal ocean: Diversity of ecosystems counts, Geophys. Res. Lett., 32, L14601, doi:10.1029/2005GL023053, 2005.

Bricker, S., Longstaff, B., Dennison, W., Jones, A., Boicourt, K., Wicks, C., and Woerner, J.: Effects of Nutrient Enrichment In the Nation's Estuaries: A Decade of Change, NOAA, MD, 2007.

Brock, T. D.: Calculating solar radiation for ecological studies, Ecol. Modell., 14, 1-19, 1981.

Caffrey, J.: Factors controlling net ecosystem metabolism in US estuaries, Estuaries, 27, 90-101, 2004.

Cai, W. J.: Estuarine and coastal ocean carbon paradox: $\mathrm{CO}_{2}$ sinks or sites of terrestrial carbon incineration?, Ann. Rev. Mar. Sci., 3, 123-145, 2011.

Cai, W. J. and Wang, Y.: The chemistry, fluxes, and sources of carbon dioxide in the estuarine waters of the Satilla and Altamaha Rivers, Georgia, Limnol. Oceanogr., 43, 657-668, 1998.

Cai, W. J., Wang, Y., and Hodson, R. E.: Acid-base properties of dissolved organic matter in the estuarine waters of Georgia, USA, Geochim. Cosmochim. Ac., 62, 473-483, 1998.

Cai, W. J., Pomeroy, L. R., Moran, M. A., and Wang, Y.: Oxygen and carbon dioxide mass balance for the estuarine-intertidal marsh complex of five rivers in the southeastern US, Limnol. Oceanogr., 44, 639-649, 1999.

Cerco, C., Kim, S.-C., and Noel, M.: The 2010 Chesapeake Bay eutrophication model, US Environmental Protection Agency Chesapeake Bay Program, Annapolis, MD, 2010.

Chen, C.-T. A., Huang, T.-H., Fu, Y.-H., Bai, Y., and He, X.: Strong sources of $\mathrm{CO}_{2}$ in upper estuaries become sinks of $\mathrm{CO}_{2}$ in large river plumes, Current Opinion in Environmental Sustainability, 4, 179-185, 2012.

Chen, C.-T. A., Huang, T.-H., Chen, Y.-C., Bai, Y., He, X., and Kang, Y.: Air-sea exchanges of $\mathrm{CO}_{2}$ in the world's coastal seas, Biogeosciences, 10, 6509-6544, doi:10.5194/bg-10-6509-2013, 2013.

Dai, T. and Wiegert, R. G.: Estimation of the primary productivity of Spartina alterniflora using a canopy model, Ecography, 19, 410423, 1996.

Dürr, H. H., Meybeck, M., and Dürr, S. H.: Lithological composition of the Earth's continental surfaces derived from a new digital map emphasizing riverine material transfer, Global Biogeochem. Cy., 19, GB4S10, doi:10.1029/2005GB002540, 2005.

Dürr, H. H., Laruelle, G. G., van Kempen, C. M., Slomp, C. P., Meybeck, M., and Middelkoop, H.: Worldwide Typology of Nearshore Coastal Systems: Defining the Estuarine Filter of River Inputs to the Oceans, Estuar. Coast., 34, 441-458, 2011.

EPA: Average annual emissions, all criteria pollutants in MS Excel, National Emissions Inventory (NEI) Air Pollutant Emissions Trends Data, Office of Air Quality Planning and Standards, available at: http://www.epa.gov/ttn/chief/trends/index.html (last access: 11 July 2014), 2009.

Fekete, B. M., Vörösmarty, C. J., and Grabs, W.: High-resolution fields of global runoff combining observed river discharge and simulated water balances, Global Biogeochem. Cy., 16, 1-10, 2002.

Fischer, H. B.: Mixing and Dispersion in Estuaries, Annu. Rev. Fluid Mech., 8, 107-133, 1976.
Friedrichs, M. A .M. and Hofmann, E. E.: Physical control of biological processes in the central equatorial Pacific Ocean, DeepSea Res. Pt. I, 48, 1023-1069, 2001.

Garcia, H. E., Locarnini, R. A., Boyer, E. W., Antonov, A., Baranova, O. K., Zweng, M. M., and Johnson, D. R.: World Ocean Atlas 2009, Volume 3: Dissolved Oxygen, Apparent Oxygen Utilization, and Oxygen Saturation, 344 pp., 2010a.

Garcia, H. E., Locarnini, R. A., Boyer, E. W., Antonov, J. I., Baranova, O. K., Zweng, M. M., and Johnson, D. R.: World Ocean Atlas 2009, Nutrients (phosphate, nitrate, silicate), 4, 398 pp., 2010b.

Garnier, J., Servais, P., Billen, G., Akopian, M., and Brion, N.: Lower Seine River and Estuary (France) Carbon and Oxygen Budgets During Low Flow, Estuaries, 24, 964-976, 2001.

GRDC: Global Freshwater Fluxes into the World Oceans/Online provided by Global Runoff Data Centre, Koblenz, Federal Institute of Hydrology (BfG), 2014.

Harrison, J. A., Caraco, N., and Seitzinger, S. P.: Global patterns and sources of dissolved organic matter export to the coastal zone: Results from a spatially explicit, global model, Global Biogeochem. Cy., 19, GB4S03, doi:10.1029/2004GB002357, 2005.

Hartmann, J., Jansen, N., Dürr, H. H., Kempe, S., and Köhler, P.: Global $\mathrm{CO}_{2}$ consumption by chemical weathering: What is the contribution of highly active weathering regions?, Glob. Planet. Change, 69, 185-194, 2009.

Hartmann, J., Dürr, H. H., Moosdorf, N., Meybeck, M., and Kempe, S.: The geochemical composition of the terrestrial surface (without soils) and comparison with the upper continental crust, Int. J. Earth Sci., 101, 365-376, 2012.

Herrmann, M., Najjar, R. G., Kemp, W. M., Alexander, R. B., Boyer, E. W., Cai, W.-J., Griffith, P. C., Kroeger, K. D., McCallister, S. L., and Smith, R. A.: Net ecosystem production and organic carbon balance of US East Coast estuaries: A synthesis approach, Global Biogeochem. Cy., 29, 96-111, doi:10.1002/2013GB004736, 2015.

Hofmann, A. F., Soetaert, K., and Middelburg, J. J.: Present nitrogen and carbon dynamics in the Scheldt estuary using a novel 1D model, Biogeosciences, 5, 981-1006, doi:10.5194/bg-5-9812008, 2008.

Hofmann, E. E., Cahill, B., Fennel, K., Friedrichs, M. A. M., Hyde, K., Lee, C., Mannino, A., Najjar, R. G., O'Reilly, J. E., Wilkin, J., and Xue, J.: Modeling the dynamics of continental shelf carbon, Ann. Rev. Mar. Sci., 3, 93-122, 2011.

Hunt, C. W., Salisbury, J. E., Vandemark, D., and McGillis, W.: Contrasting Carbon Dioxide Inputs and Exchange in Three Adjacent New England Estuaries, Estuar. Coast., 34, 68-77, doi:10.1007/s12237-010-9299-9, 2010.

Hunt, C. W., Salisbury, J. E., Vandemark, D., and McGillis, W.: Contrasting Carbon Dioxide Inputs and Exchange in Three Adjacent New England Estuaries, Estuar. Coast., 34, 68-77, 2011.

Ippen, A. T. and Harleman, D. R. F.: One-dimensional Analysis of Salinity Intrusion in Estuaries, Technical Bulletin No. 5, Committee on Tidal Hydraulics, Corps of Engineers, US Army, Vicksburg, 1961.

Jiang, L. Q., Cai, W. J., and Wang, Y.: A comparative study of carbon dioxide degassing in river- and marine-dominated estuaries, Limnol. Oceanogr., 53, 2603-2615, 2008. 
Jiang, L.-Q., Cai, W.-J., Wang, Y., and Bauer, J. E.: Influence of terrestrial inputs on continental shelf carbon dioxide, Biogeosciences, 10, 839-849, doi:10.5194/bg-10-839-2013, 2013.

Joesoef, A., Huang, W.-J., Gao, Y., and Cai, W.-J.: Air-water fluxes and sources of carbon dioxide in the Delaware Estuary: spatial and seasonal variability, Biogeosciences, 12, 6085-6101, doi:10.5194/bg-12-6085-2015, 2015.

Kent, B. H.: Turbulent diffusion in a Sectionally Homogeneous Estuary, Technical Report 16, Chesapeake Bay Institute, John Hopkins, University, Baltimore, 1958.

Key, R. M., Kozyr, A., Sabine, C. L., Lee, K., Wanninkhof, R., Bullister, J. L., Feely, R. A., Millero, F. J., Mordy, C., and Peng, T. H.: A global ocean carbon climatology: Results from Global Data Analysis Project (GLODAP), Global Biogeochem. Cy., 18, 1-23, 2004.

Laruelle, G. G.: Quantifying nutrient cycling and retention in coastal waters at the global scale, Ph.D. dissertation, Utrecht University, 2009.

Laruelle, G. G., Regnier, P., Ragueneau, O., Kempa, M., Moriceau, B., Ni Longphuirt, S., Leynaert, A., Thouzeau, G., and Chauvaud, L.: Benthic-pelagic coupling and the seasonal silica cycle in the Bay of Brest (France): new insights from a coupled physical-biological model, Mar. Ecol.-Prog. Ser., 385, 15-32, 2009.

Laruelle, G. G., Dürr, H. H., Slomp, C. P., and Borges, A. V.: Evaluation of sinks and sources of $\mathrm{CO}_{2}$ in the global coastal ocean using a spatially-explicit typology of estuaries and continental shelves, Geophys. Res. Lett., 37, L15607, doi:10.1029/2010GL043691, 2010.

Laruelle, G. G., Dürr, H. H., Lauerwald, R., Hartmann, J., Slomp, C. P., Goossens, N., and Regnier, P. A. G.: Global multi-scale segmentation of continental and coastal waters from the watersheds to the continental margins, Hydrol. Earth Syst. Sci., 17, 2029-2051, doi:10.5194/hess-17-2029-2013, 2013.

Laruelle, G. G., Lauerwald, R., Rotschi, J., Raymond, P. A., Hartmann, J., and Regnier, P.: Seasonal response of air-water $\mathrm{CO}_{2}$ exchange along the land-ocean aquatic continuum of the northeast North American coast., Biogeosciences, 12, 1447-1458, doi:10.5194/bg-12-1447-2015, 2015.

Lauerwald, R., Hartmann, J., Moosdorf, N., Kempe, S., and Raymond, P.A.: What controls the spatial patterns of the riverine carbonate system? - A case study for North America, Chem. Geol., 337/338, 114-127, 2013.

Lauerwald, R., Laruelle, G. G., Hartmann, J., Ciais, P., and Regnier, P. A. G.: Spatial patterns in $\mathrm{CO}_{2}$ evasion from the global river network, Global Biogeochem. Cy., 29, 534-554, doi:10.1002/2014GB004941, 2015.

Leonard, B.: Third-Order Upwinding as a Rational Basis for Computational Fluid Dynamics, in: Computational Techniques and Applications: CTAC-83, edited by: Noye, J. and Fletcher, C. A. J., Elsevier, North-Holland, 1984.

Le Quéré, C., Peters, G. P., Andres, R. J., Andrew, R. M., Boden, T. A., Ciais, P., Friedlingstein, P., Houghton, R. A., Marland, G., Moriarty, R., Sitch, S., Tans, P., Arneth, A., Arvanitis, A., Bakker, D. C. E., Bopp, L., Canadell, J. G., Chini, L. P., Doney, S. C., Harper, A., Harris, I., House, J. I., Jain, A. K., Jones, S. D., Kato, E., Keeling, R. F., Klein Goldewijk, K., Körtzinger, A., Koven, C., Lefèvre, N., Maignan, F., Omar, A., Ono, T., Park, G.-H., Pfeil, B., Poulter, B., Raupach, M. R., Regnier, P., Röden- beck, C., Saito, S., Schwinger, J., Segschneider, J., Stocker, B. D., Takahashi, T., Tilbrook, B., van Heuven, S., Viovy, N., Wanninkhof, R., Wiltshire, A., and Zaehle, S.: Global carbon budget 2013, Earth Syst. Sci. Data, 6, 235-263, doi:10.5194/essd-6-2352014, 2014.

Le Quéré, C., Moriarty, R., Andrew, R. M., Canadell, J. G., Sitch, S., Korsbakken, J. I., Friedlingstein, P., Peters, G. P., Andres, R. J., Boden, T. A., Houghton, R. A., House, J. I., Keeling, R. F., Tans, P., Arneth, A., Bakker, D. C. E., Barbero, L., Bopp, L., Chang, J., Chevallier, F., Chini, L. P., Ciais, P., Fader, M., Feely, R. A., Gkritzalis, T., Harris, I., Hauck, J., Ilyina, T., Jain, A. K., Kato, E., Kitidis, V., Klein Goldewijk, K., Koven, C., Landschützer, P., Lauvset, S. K., Lefèvre, N., Lenton, A., Lima, I. D., Metzl, N., Millero, F., Munro, D. R., Murata, A., Nabel, J. E. M. S., Nakaoka, S., Nojiri, Y., O’Brien, K., Olsen, A., Ono, T., Pérez, F. F., Pfeil, B., Pierrot, D., Poulter, B., Rehder, G., Rödenbeck, C., Saito, S., Schuster, U., Schwinger, J., Séférian, R., Steinhoff, T., Stocker, B. D., Sutton, A. J., Takahashi, T., Tilbrook, B., van der Laan-Luijkx, I. T., van der Werf, G. R., van Heuven, S., Vandemark, D., Viovy, N., Wiltshire, A., Zaehle, S., and Zeng, N.: Global Carbon Budget 2015, Earth Syst. Sci. Data, 7, 349-396, doi:10.5194/essd-7-349-2015, 2015.

Lin, J., Xie, L., Pietrafesa, L. J., Ramus, J. S., and Paerl, H.W.: Water Quality Gradients across Albemarle-Pamlico Estuarine System: Seasonal Variations and Model Applications, J. Coast. Res., 23, 213-229, 2007.

Locarnini, R. A., Mishonov, A. V., Antonov, J. I., Boyer, T. P., Garcia, H. E., Baranova, O. K., Zweng, M. M., and Johnson, D. R.: World Ocean Atlas 2009, Temperature, 1, 2010.

Ludwig, W., Probst, J. L., and Kempe, S.: predicting the oceanic input of organic carbon by continental erosion, Global Biogeochem. Cy., 10, 23-41, 1996.

Maher, D. T. and Eyre, B. D.: Carbon budgets for three autotrophic Australian estuaries: Implications for global estimates of the coastal air-water $\mathrm{CO}_{2}$ flux, Global Biogeochem. Cy., 26, GB1032, doi:10.1029/2011GB004075, 2012.

Mateus, M., Vaz, N., and Neves, R.: A process-oriented model of pelagic biogeochemistry for marine systems, Part II: Application to a mesotidal estuary, J. Mar. Syst., 94, 90-101, 2012.

Mayorga, E., Seitzinger, S. P., Harrison, J. A., Dumont, E., Beusen, A. H. W., Bouwman, A. F., Fekete, B. M., Kroeze, C., and Van Drecht, G.: Global Nutrient Export from WaterSheds 2 (NEWS 2): Model development and implementation. Environmental Modelling and Software, 25, 837-853, 2010.

Meybeck, M.: Carbon, nitrogen, and phosphorus transport by world rivers, Am. J. Sci., 282, 401-450, 1982.

Meybeck, M., Dürr, H. H., and Vörosmarty, C. J.: Global coastal segmentation and its river catchment contributors: A new look at land-ocean linkage, Global Biogeochem. Cy., 20, GB1S90, doi:10.1029/2005GB002540, 2006.

Middelburg, J. J., Klaver, G., Nieuwenhuize, J., Wielemaker, A., De Haas, W., Vlug, T., and Van Der Nat, J. F. W. A.: Organic matter mineralization in intertidal sediments along an estuarine gradient, Mar. Ecol. Prog. Ser., 132, 157-168, 1996.

Najjar, R. G., Friedrichs, M., and Cai, W.-J. (Eds.): Report of The US East Coast Carbon Cycle Synthesis Workshop, 19-20 January 2012, Ocean Carbon and Biogeochemistry Program and North American Carbon Program, 34 pp., 2012. 
NASA/NGA: SRTM Water Body Data Product Specific Guidance, Version 2.0, 2003.

Nihoul, J. C. J. and Ronday, F.: Modèles d'estuaires partiellement stratifiés, Projet Mer, Service de la Programmation Scientifique, Bruxelles, Belgium, 10, 71-98, 1976.

Nixon, S. W., J. W. Ammerman, L. P. Atkinson, V. M. Berounsky, G. Billen, W. C. Boicourt, W. R. Boynton, T. M. Church, D. M. Ditoro, R. Elmgren, J. H. Garber, A. E. Giblin, R. A. Jahnke, N. J. P. Owens, M. E. Q. Pilson, and Seitzinger, S. P.: The fate of nitrogen and phosphorus at the land-sea margin of the North Atlantic Ocean, Biogeochemistry, 3, 141-180, 1996.

NOAA: National Estuarine Inventory Data Atlas, Volume 1: Physical and Hydrologic Characteristics, National Oceanic and Atmospheric Administration, MD, 1985.

Odum, H. T.: Primary Production in Flowing Waters, Limnol. Oceanogr., 1, 102-117, 1956.

O'Kane, J. P.: Estuarine Water Quality Management, Pitman, London, UK, 1980.

Platt, T., Gallegos, C. L., and Harrison, W. G.: Photoinhibition of photosynthesis in natural assemblages of marine phytoplankton, J. Mar. Res., 38, 687-701, 1980.

Preddy, W. S.: The mixing and movement of water in the estuary of the Thames, J. Mar. biol. Ass. UK, 33, 645-662, 1954.

Press, W. H., Teukolosky, S. A., Vetterling, W. T., and Flannery, B. P.: Numerical Recipes in C: The Art of Scientific Programming, 2nd Edn., Cambridge University Press, USA, 1992.

Pritchard, D. W.: The Equations of Mass Continuity and Salt Continuity in Estuaries, J. Mar. Res., 15, 33-42, 1958.

Raymond, P. A. and Hopkinson, C. S.: Ecosystem Modulation of Dissolved Carbon Age in a Temperate Marsh-Dominated Estuary, Ecosystems, 6, 694-705, 2003.

Raymond, P. A., Caraco, N. F., and Cole, J. J.: Carbon dioxide concentration and atmospheric flux in the Hudson River, Estuaries, 20, 381-390, 1997.

Raymond, P. A., Bauer, J. E., and Cole, J. J.: Atmospheric $\mathrm{CO}_{2}$ evasion, dissolved inorganic carbon production, and net heterotrophy in the York River estuary, Limnol. Oceanogr., 45, 17071717, 2000.

Raymond, P. A., Hartmann, J., Lauerwald, R., Sobek, S., McDonald, C., Hoover, M., Butman, D., Striegl, R., Mayorga, E., Humborg, C., Kortelainen, P., Dürr, H., Meybeck, M., Ciais, P., and Guth, P.: Global carbon dioxide emissions from inland waters, Nature, 503, 355-359, 2013.

Regnier, P. and Steefel, C. I.: A high resolution estimate of the inorganic nitrogen flux from the Scheldt estuary to the coastal North Sea during a nitrogen-limited algal bloom, spring 1995, Geochim. Cosmochim. Ac., 63, 1359-1374, 1999.

Regnier, P., Wollast, R., and Steefel, C. I.: Long-term fluxes of reactive species in macrotidal estuaries: Estimates from a fully transient, multicomponent reaction-transport model, Mar. Chem., 58, 127-145, 1997.

Regnier, P., Mouchet, A., Wollast, R., and Ronday, F.: A discussion of methods for estimating residual fluxes in strong tidal estuaries, Cont. Shelf Res., 18, 1543-1571, 1998.

Regnier, P., Vanderborght, J. P., Steefel, C. I., and O'Kane, J. P.: Modeling complex multi-component reactive-transport systems: Towards a simulation environment based on the concept of a Knowledge Base, Appl. Math. Model., 26, 913-927, 2002.
Regnier, P., Friedlingstein, P., Ciais, P., Mackenzie, F. T., Gruber, N., Janssens, I. A., Laruelle, G. G., Lauerwald, R., Luyssaert, S., Andersson, A. J., Arndt, S., Arnosti, C., Borges, A. V., Dale, A. W., Gallego-Sala, A., Godderis, Y., Goossens, N., Hartmann, J., Heinze, C., Ilyina, T., Joos, F., LaRowe, D. E., Leifeld, J., Meysman, F. J. R., Munhoven, G., Raymond, P. A., Spahni, R., Suntharalingam, P., and Thullner, M.: Anthropogenic perturbation of the carbon fluxes from land to ocean, Nat. Geosci., 6, 597-607, 2013a.

Regnier, P., Arndt, S., Goossens, N., Volta, C., Laruelle, G. G., Lauerwald, R., and Hartmann, J.: Modelling Estuarine Biogeochemical Dynamics: From the Local to the Global Scale, Aquat. Geochem., 19, 591-626, 2013b.

Riemann, B., Simonsen, P., and Stensgaard, L.: The carbon and chlorophyll content of phytoplankton from various nutrient regimes, J. Plank. Res., 11, 1037-1045, 1989.

Rossow, W. B., and Schiffer, R. A.: Advances in understanding clouds from ISCCP, Bull. Amer. Meteorol. Soc., 80, 2261-2288, doi:10.1175/1520-0477(1999)080<2261:AIUCFI>2.0.CO;2, 1999.

Sarma, V. V. S. S., Viswanadham, R., Rao, G. D., Prasad, V. R., Kumar, B. S. K., Naidu, S. A., Kumar, N. A., Rao, D. B., Sridevi, T., Krishna, M. S., Reddy, N. P. C., Sadhuram, Y., and Murty, T. V. R.: Carbon dioxide emissions from Indian monsoonal estuaries, Geophys. Res. Lett., 39, L03602, doi:10.1029/2011GL050709, 2012.

Savenije, H. H. G.: A one-dimensional model for salinity intrusion in alluvial estuaries, J. Hydrol., 85, 87-109, 1986. Savenije, H. H. G.: Lagrangian solution of St. Venant's equations for alluvial estuary, J. Hydraul. Engin., 118, 1153-1163, 1992.

Savenije, H. H. G. (Ed.): Salinity and Tides in Alluvial Estuaries, 1st Edn., Elsevier, Amsterdam, 2005.

Savenije, H. H. G. (Ed.): Salinity and Tides in Alluvial Estuaries, 2nd Edn., available at: http://salinityandtides.com (last access: 8 March 2015), 2012.

Seitzinger, S. P., Harrison, J. A., Dumont, E., Beusen, A. H. W., and Bouwman, A. F.: Sources and delivery of carbon, nitrogen, and phosphorus to the coastal zone: An overview of Global Nutrient Export from Watersheds (NEWS) models and their application, Global Biogeochem. Cy., 19, GB4S01, doi:10.1029/2005GB002606, 2005.

Schwarz, G. E., Hoos, A. B., Alexander, R. B., and Smith, R. A.: The SPARROW Surface Water-Quality Model: Theory, Application and User Documentation, US Geological Survey, Techniques and Methods Report, Book 6, Chapter B3, Reston, Virginia, 2006

Sharp, J. H., Yoshiyama, K., Parker, Schwartz, M. C., Curless, S. E., Beauregard, A. Y., Ossolinski, J. E., and Davis, A. R.: A Biogeochemical View of Estuarine Eutrophication: Seasonal and Spatial Trends and Correlations in the Delaware Estuary, Estuar. Coast., 32, 1023-1043, doi:10.1007/s12237-009-9210-8, 2009.

Sharp, J. H.: Estuarine oxygen dynamics: What can we learn about hypoxia from long-time records in the Delaware Estuary?, Limnol. Oceanogr., 55, 2010, 535-548, 2010.

Shih, J.-S., Alexander, R. B., Smith, R. A., Boyer, E. W., Schwarz, G. E., and Chung, S.: An initial SPARROW model of land use and in-stream controls on total organic carbon in streams of the conterminous United States, US Geological Survey, Reston, Virginia, 2010. 
Signorini, S. R., Mannino, A., Najjar Jr., R. G., Friedrichs, M. A. M., Cai, W. J., Salisbury, J., Wang, Z. A., Thomas, H., and Shadwick, E.: Surface ocean $p \mathrm{CO}_{2}$ seasonality and sea-air $\mathrm{CO}_{2}$ flux estimates for the North American east coast, J. Geophys. Res.Ocean., 118, 5439-5460, 2013.

Simmons, H. B.: Some effects of inland discharge on estuarine hydraulics, Proc. Am. Soc. Civ. Eng.-ASCE, 81, p. 792, 1955.

Soetaert, K. and Herman, P. M. J.: Nitrogen dynamics in the Westerschelde estuary (SW Netherlands) estimated by means of the ecosystem model MOSES, Hydrobiologia, 311, 225-246, 1995.

Stets, E. G. and Strieg, R. G.: Carbon export by rivers draining the conterminous united states, Inland Waters, 2, 177-184, 2012.

Stigter, C. and Siemons, J.: Calculation of longitudinal salt distribution in estuaries as function of time, Publication Delft Hydraulics Laboratory, the Netherlands, 52, 1967.

Tian, H., Chen, G., Liu, M., Zhang, C., Sun, G., Lu, C., Xu, X., Ren, W., Pan, S., and Chappelka, A.: Model estimates of net primary productivity, evapotranspiration, and water use efficiency in the terrestrial ecosystems of the southern United States during 18952007, Forest Ecol. Manag., 259, 1311-1327, 2010.

Tian, H., Chen, G., Zhang, C., Liu, M., Sun, G., Chappelka, A., Ren, W., Xu, X., Lu, C., Pan, S., Chen, H., Hui, D., McNulty, S., Lockaby, G., and Vance, E.: Century-Scale Responses of Ecosystem Carbon Storage and Flux to Multiple Environmental Changes in the Southern United States, Ecosystems, 15, 674-694, 2012.

US Fish and Wildlife Service: National Wetlands Inventory website, US Department of the Interior, Fish and Wildlife Service, Washington, DC http://www.fws.gov/wetlands/ (last accessed: February 2015), 2014.
Vanderborght, J. P., Wollast, R., Loijens, M., and Regnier, P.: Application of a transport-reaction model to the estimation of biogas fluxes in the Scheldt Estuary, Biogeochemistry, 59, 207-237, 2002.

Vanderborght, J. P., Folmer, I., Aguilera, D. R., Uhrenholdt, T., and Regnier, P.: Reactive-transport modelling of a river-estuarinecoastal zone system: application to the Scheldt estuary, Mar. Chem., 106, 92-110, 2007.

Volta, C., Arndt, S., Savenije, H. H. G., Laruelle, G. G., and Regnier, P.: C-GEM (v 1.0): a new, cost-efficient biogeochemical model for estuaries and its application to a funnel-shaped system, Geosci. Model Dev., 7, 1271-1295, doi:10.5194/gmd-7-12712014, 2014.

Volta, C., Laruelle, G. G., and Regnier, P.: Regional carbon and $\mathrm{CO}_{2}$ budgets of North Sea tidal estuaries, Estuar. Coast. Shelf Sci., 176, 76-90, 2016a.

Volta, C., Laruelle, G. G., Arndt, S., and Regnier, P.: Linking biogeochemistry to hydro-geometrical variability in tidal estuaries: a generic modeling approach, Hydrol. Earth Syst. Sci., 20, $991-$ 1030, doi:10.5194/hess-20-991-2016, 2016b.

Vörösmarty, C. J., Fekete, B., and Tucker, B. A.: River Discharge Database, Version 1.0 (RivDIS v1.0), Volumes 0 through 6. A contribution to IHP-V Theme 1, Technical Documents in Hydrology Series, UNESCO, Paris, 1996.

Wang, Z. A. and Cai, W. J.: Carbon dioxide degassing and inorganic carbon export from a marsh-dominated estuary (the Duplin River): A marsh $\mathrm{CO}_{2}$ pump, Limnol. Oceanogr., 49, 341-354, 2004.

Zeebe, R. E. and Wolf-Gladrow, D. (Eds.): $\mathrm{CO}_{2}$ in seawater: equilibrium, kinetics, isotopes, Elsevier, Amsterdam, 2001. 